\title{
1 A microtranslatome coordinately regulates sodium and potassium currents in
}

\section{2 the heart}

3

4

5

6

7

8

Catherine A. Eichel ${ }^{1}$, Erick B. Ríos-Pérez ${ }^{1}$, Fang Liu ${ }^{1}$, Margaret B. Jameson ${ }^{1}$, David K. Jones ${ }^{1,2}$, Jennifer J. Knickelbine ${ }^{1}$ and Gail A. Robertson ${ }^{1 *}$

${ }^{1}$ Dept. of Neuroscience and Cardiovascular Research Center University of Wisconsin School of Medicine and Public Health 1111 Highland Ave. \#5505

Madison, WI 53705

${ }^{2}$ Current address: Dept. of Pharmacology University of Michigan Medical School

Ann Arbor, Ml 48109

*Corresponding author: garobert@wisc.edu

Keywords: action potential, ion channels, co-knockdown, arrhythmia, $\mathrm{KCNH} 2, \mathrm{Kv11.1,}$ $\mathrm{Na}_{v} 1.5$, cotranslational

\section{ABBREVIATION LIST}

AP: Action potential

APD: Action potential duration

Co-IP: Co-immunoprecipitation

ER: Endoplasmic reticulum

FISH: Fluorescence in-situ hybridization

IF: Immunofluorescence

IP: Immunoprecipitation

IPSC-CM: Cardiomyocyte derived from induced pluripotent stem cells

RBP: RNA binding protein

RNA-IP: RNA-immunoprecipitation

shRNA: Short hairpin RNA 


\section{ABSTRACT}

48

49 Catastrophic arrhythmias and sudden cardiac death can occur with even a small imbalance

50 between inward sodium currents and outward potassium currents, but mechanisms

51 establishing this critical balance are not understood. Here, we show that mRNA transcripts

52 encoding $I_{\mathrm{Na}}$ and $I_{\mathrm{Kr}}$ channels (SCN5A and $h E R G$, respectively) are associated in defined

53 complexes during protein translation. Using biochemical, electrophysiological and single-

54 molecule fluorescence localization approaches, we find that roughly half the $h E R G$

55 translational complexes contain SCN5A transcripts. Moreover, the transcripts are regulated

56 in a way that alters functional expression of both channels at the membrane. Association and

57 coordinate regulation of transcripts in discrete "microtranslatomes" represents a new

58 paradigm controlling electrical activity in heart and other excitable tissues.

59

60

61

62

63

64 


\section{INTRODUCTION}

Signaling in excitable cells depends on the coordinated flow of inward and outward currents through a defined ensemble of ion channel species. This is especially true in heart, where the expression of many different ion channels controls the spread of excitation triggering the concerted contraction of the ventricular myocardium. Even small perturbations in the quantitative balance due to block or mutations affecting a single type of channel can initiate or perpetuate arrhythmias and lead to sudden death. Repolarization is a particularly vulnerable phase of the cardiac cycle, when imbalance of inward and outward currents can prolong action potential duration and trigger arrhythmias such as Torsades de Pointes ${ }^{1}$. The genetic basis of such catastrophic arrhythmias is in many cases unknown; mechanisms coordinating expression of multiple ion channels may represent novel disease targets.

Cardiac $I_{\mathrm{Kr}}$ is critical for normal repolarization ${ }^{2}$ and is a major target of acquired and congenital long QT syndrome ${ }^{3,4}$. $l_{\mathrm{Kr}}$ channels minimally comprise hERG1a and hERG1b subunits $^{5,6}$, which associate cotranslationally ${ }^{7}$ and preferentially form heteromultimers ${ }^{8}$. Underlying heteromultimerization is the cotranslational association of $h E R G 1 a$ and $1 b$ mRNA transcripts $^{9}$. Because current magnitude is greater in heteromeric hERG1a/1b vs. homomeric hERG1a channels, and loss of hERG1b is pro-arrhythmic ${ }^{5,10}$, the mechanism of cotranslational assembly of hERG subunits is important in cardiac repolarization ${ }^{9}$.

\section{In this study we found that association of transcripts could occur not only between alternate} $h E R G$ transcripts encoded by a single gene locus, but also between transcripts encoding entirely different ion channel types whose balance is critical to cardiac excitability. Indeed, we show that $S C N 5 A$, encoding the cardiac $\mathrm{Na}_{v} 1.5$ sodium channel, associates with $h E R G$ transcripts as demonstrated by co-immunoprecipitation of nascent protein in heterologous expression systems, cardiomyocytes derived from human induced pluripotent stem cells, and native human myocardium. Single-molecule fluorescent in situ hybridization (smFISH) 
93 quantitatively reveals $h E R G$ and $S C N 5 A$ transcript colocalization captured during protein

94 translation. Targeting $h E R G$ transcripts for shRNA degradation coordinately reduces SCN5A

95 transcript levels as well, along with native $I_{K r}$ and $I_{N a}$ currents recorded from cardiomyocytes.

96 Thus, cotranslational association and regulation of transcripts is a novel mechanism

97 establishing and preserving a balance of $I_{K r}$ and $I_{N a}$ in heart, where relative levels of these

98 currents are critical for normal action potential production and coordinated electrical activity.

99

100

101

102

103

104

105 


\section{RESULTS}

107 Copurification of hERG $1 a$ and SCN5A transcripts with their encoded proteins

108 Using specific antibodies that target the N-terminus of hERG1a, we purified hERG1a protein

109 from induced pluripotent stem cell-derived cardiomyocytes (iPSC-CMs) and human ventricle

110 lysates and performed RT-PCR to identify associated transcripts ("RNA-IP”; Fig. 1a). As

111 previously reported ${ }^{9}$, both $h E R G 1 a$ and $1 b$ transcripts co-immunoprecipitated with nascent

112 hERG 1a protein. Surprisingly, SCN5A transcripts encoding $\mathrm{Na}_{v} 1.5$ channels also copurified

113 with nascent hERG1a protein (Fig. 1b and Supplementary Fig. S1). The interaction appears

114 specific since neither ryanodine receptor RyR2 nor inward rectifier channel Kir2.1 (KCNJ2)

115 transcripts copurified as part of this complex. The counterpart experiment using anti-Na 1.5

116 antibodies confirmed association of transcripts encoding hERG1a, hERG1b and $\mathrm{Na}_{\vee} 1.5$, but

117 not RyR2 (Fig. 1b). Bead-only controls showed no signal, indicating specific interactions of

118 antibodies with corresponding antigens. The association also occurred in HEK293 cells,

119 where additional controls showed that the antibodies used did not interact nonspecifically

120 with mRNA encoding the other ion channels or subunits (Supplementary Fig. S1).

121 Interestingly, when lysates independently expressing hERG1a and $\mathrm{Na}_{v} 1.5$ were mixed,

122 hERG1a antibodies copurified only hERG1a mRNA, and Nav1.5 antibodies copurified only

123 SCN5A mRNA, indicating that association of the two mRNAs requires their co-expression in

124 situ. In addition, the interaction between hERG1a and SCN5A does not require the presence

125 of $h E R G 1 b$ (Supplementary Fig. S1). This experiment demonstrates that transcripts

126 encoding hERG1a, hERG1b and $\mathrm{Na}_{\mathrm{v}} 1.5$ physically interact within the cell and can be

127 copurified using antibodies targeting either nascent $\mathrm{hERG} 1 \mathrm{a}$ or $\mathrm{Na}_{\mathrm{v}} 1.5$ proteins. Their

128 association with either encoded protein implies the transcripts associate during protein

129 translation, or cotranslationally.

\section{1 hERG1a and SCN5A transcript distribution}

132 To independently confirm hERG1a and SCN5A transcript association, we performed single-

133 molecule fluorescence in situ hybridization (smFISH) experiments in iPSC-CMs (Fig. 2a). We 
134 used a combination of short DNA oligonucleotides (20 nucleotides), each labelled with a

135 single fluorophore, that bind in series on the target mRNA and collectively are detected as a

136 single fluorescent spot $^{11}$ (see Methods). Probes for $h E R G 1 a$ and SCN5A mRNAs were

137 designed with spectrally separable labels for simultaneous detection (Quasar 647 and 546

138 respectively; see Methods and Supplementary Fig. S2 for probe validation, and Table S1 for

139 list of probes) $)^{12}$. Punctate signal for each mRNA species appeared singly and in clusters (Fig.

140 1a, b). To evaluate mRNA copy number in each detected signal, we fitted the histogram of

141 the total fluorescence intensity of smFISH signals with the sum of Gaussian functions and

142 determined mean intensity of a single mRNA molecule for each species (Fig. 2b and

143 Supplementary Fig. S3). We found that approximately $25 \%$ of detected molecules exist

144 singly, whereas about $20 \%$ occupy clusters containing 6 or more transcripts (Fig. 2c). Both

145 transcripts were observed throughout the cytoplasm with higher density within 5-10 $\mu \mathrm{m}$ from

146 the nucleus (Fig. 2a, d), consistent with the expected distribution of perinuclear endoplasmic

147 reticulum where these mRNA molecules are translated into proteins. A GAPDH mRNA probe

148 set served as a positive control for smFISH experiments (Stellaris ${ }^{\circledR}$ validated control). In

149 contrast with signals observed for $h E R G 1 a$ and SCN5A transcripts, GAPDH transcript

150 clustered less, with $50 \%$ found as single molecules and $<5 \%$ in clusters of 6 or more

151 transcripts (Fig. 2c). Moreover, GAPDH molecules distributed more homogeneously

152 throughout the cytoplasm with higher density in the range of 10 to $20 \mu \mathrm{m}$ from the nucleus

153 (Fig. 2d). We noted similar numbers of $h E R G 1 a$ and SCN5A transcripts per cell but fewer

154 than those for GAPDH (Fig. 2e). Thus, numbers and spatial distribution of $h E R G 1 a$ and

$155 S C N 5 A$ transcripts can be simultaneously resolved. Further work will be required to elucidate

156 the significance or possible physiological role of differently sized mRNA clusters.

\section{7}

158 hERG1a and SCN5A transcript expression levels correlate

159 Although we observed a range in numbers of $h E R G 1 a$ and SCN5A mRNAs among iPSC-

$160 \mathrm{CMs}$ (Fig. 2e), regression analysis revealed clear correlation in their expression levels within 
161 a given cell (Fig. 3 and Supplementary Table S3). Plotted against each other, hERG1a and

162 SCN5A mRNA numbers exhibited a coefficient of determination $\left(R^{2}\right)$ of $0.57(P=0.00001 ; 41$

163 cells; Fig. 3a and b). In contrast, pairwise combinations of hERG1a and RyR2, hERG1a and

$164 \mathrm{GAPDH}$, or $S C N 5 A$ and $G A P D H$ exhibited much lower linear correlation $\left(\mathrm{R}^{2}=0.22, \mathrm{P}=0.017\right.$;

$165 R^{2}=0.18, P=0.15 ;$ and $R^{2}=0.33, P=0.000134$ respectively; $n=26,13$, and 28 cells respectively;

166 Fig. 3c and d, Supplementary Fig. S5 a and b, and Supplementary Table S3). Spearman

167 coefficients revealed similar results as Pearson coefficients, where significant correlation is

168 observed only between SCN5A and hERG1a (Supplementary Table S3). These findings

169 indicate a roughly constant ratio of $h E R G 1 a$ and SCN5A mRNA copies.

hERG1a and SCN5A transcripts colocalize

172 To determine potential $h E R G 1 a$ and SCN5A transcript association using SmFISH, we

173 measured proximity between the two signals using the centroid position, scored from

174 touching to $67 \%$ (1 pixel) overlap (Fig. 4a and b). To discern colocalization from random

175 overlap, we calculated the expected number of particles that could associate based on

176 chance only for the different association criteria. Two-tailed $t$ tests with Bonferroni correction

177 revealed association between $h E R G 1 a$ and SCN5A transcripts significantly greater than that

178 expected by chance (see Methods; P values summarized in Supplementary Table S2; Fig.

179 4b). Approximately $25 \%$ of each transcript population was associated with the other (Fig. 4c).

180 To test specificity of interaction between $h E R G 1 a$ and SCN5A transcripts, smFISH and

181 pairwise comparisons were also performed with RyR2 and GAPDH transcripts, which

182 revealed no significant association (Fig. 4d and e; Supplementary Table S2). These results

183 show that association of $h E R G$ and SCN5A transcripts demonstrated in lysates can also be

184 visualized in iPSC-CMs in situ, and provide strong evidence for the existence of a discrete

185 mRNA complex comprising hERG1a and SCN5A transcripts.

186

187

188 


\section{Discrete hERG1a and SCN5A cotranslational complexes}

190 To further explore whether colocalized mRNAs were part of a translational complex, we

191 combined smFISH with immunofluorescence using hERG1a antibodies. We observed close

192 association between $h E R G 1 a$ and SCN5A mRNAs and hERG1a protein significantly greater

193 than that expected by chance (Fig. 5a and b and Supplementary Fig. S6a and b).

194 Interestingly, among the $16 \%$ of actively translated $h E R G 1$ a mRNAs (i.e. those associated

195 with hERG1a protein), 46\% were also associated with SCN5A mRNAs (Fig. 5c), indicating a

196 3-fold enrichment of their association in translational complexes. Analysis of the distribution

197 of colocalized molecules revealed that $70 \%$ are located close to the nucleus (within $10 \mu \mathrm{m}$,

198 Fig. 5d).

200 We monitored association of hERG1a protein and transcript in the presence of puromycin,

201 which releases translating ribosomes from mRNAs ${ }^{13}$ (Fig. 6a). We observed no change due

202 to puromycin in the total number of respective mRNAs detected per cell (Fig. 6b). As

203 expected, puromycin reduced association between $h E R G 1$ a mRNA and hERG1a protein

204 (antibody) and the S6 ribosomal protein (Fig. 6c). In addition, triple colocalization of $h E R G 1 a$

205 and SCN5A transcripts and either hERG1a protein or the ribosomal subunit S6 was robustly

206 reduced (Fig 6d). These findings further support the conclusion that $h E R G 1 a$ and SCN5A

207 associate cotranslationally.

208

hERG1a and SCN5A mRNAs are coregulated

210 We previously demonstrated that targeted knockdown of either $h E R G 1 \mathrm{a}$ or $1 \mathrm{~b}$ transcripts by

211 specific short hairpin RNA (shRNA) caused a reduction of both transcripts not attributable to

212 off-target effects in iPSC-CMs or in HEK293 cells ${ }^{9}$. To determine whether $h E R G$ and SCN5A

213 transcripts are similarly subject to this co-knockdown effect, we evaluated expression levels

214 by performing RT-qPCR experiments in iPSC-CM. We found that $h E R G 1 a, h E R G 1 b$ and

$215 S C N 5 A$ expression levels were all reduced by about $50 \%$ upon $h E R G 1$ a silencing compared

216 to the effects of a scrambled shRNA (Fig. 7a, orange bars). RYR2 transcript levels were 
217 unaffected. We observed similar results using the specific hERG1b shRNA (Fig. 7a, blue

218 bars). Expressed independently in HEK293 cells, only hERG1a mRNA was affected by the

219 1a shRNA, and only $h E R G 1 b$ was affected by the 1b shRNA (Fig. 7b). SCN5A was

220 unaffected by either shRNA, indicating that the knockdown in iPSC-CMs was not due to off-

221 target effects and levels of associated $h E R G 1 a$ and SCN5A are quantitatively coregulated.

222 Similar results of approximately 40\% co-knockdown of discrete $h E R G 1 a$ and SCN5A mRNA

223 particles were obtained using smFISH (Supplementary Fig. S7). Even more than the total

224 population of mRNA, the number of colocalized particles is decreased by approximately

$22555 \%$, indicating that physically associated transcripts are subjected to co-knockdown (Fig.

$226 \mathrm{~S} 7 \mathrm{c}$ ). Together these results indicate a coordinated and quantitative regulation of mRNAs

227 encoding a complement of ion channels.

\section{$I_{\mathrm{Kr}}$ and $I_{\mathrm{Na}}$ are coregulated}

230 To assess functional consequences of transcript coregulation, we recorded effects of

$231 h E R G 1 b$ silencing on native currents in iPSC-CMs. Fig. 7c shows the repolarizing current $I_{\mathrm{Kr}}$

232 in iPSC-CMs transfected with either hERG1b or scrambled shRNA. Steady state and peak

233 tail $I_{\mathrm{Kr}}$ were decreased in $h E R G 1 b$-silenced cells compared to cells transfected with

234 scrambled shRNA (Fig. 7d). $I_{\mathrm{Kr}}$ reduction was the result of a decrease in $\mathrm{G}_{\max }$ upon hERG1b-

235 specific silencing with no modifications in the voltage dependence of activation (Fig. 7e and

236 Supplementary Table S4). These results are in accordance to our previous studies reporting

237 a reduction in $I_{\mathrm{Kr}}$ density upon $h E R G 1 b$-specific silencing, and indicate that transcripts

238 targeted by shRNA are those undergoing translation ${ }^{9,10}$. To determine whether $h E R G 1 b$

239 silencing also affects translationally active $S C N 5 A$, we measured peak $I_{\mathrm{Na}}$ density in iPSC-

$240 \mathrm{CMs}$ and detected significant reduction of about $60 \%$ when $h E R G 1 b$ was silenced, compared

241 to control cells (Fig. $7 f, g$ and $h$ ). Peak $G_{\max }$ was decreased but no alterations in voltage

242 dependence of activation or inactivation were detected (Fig. 7h and Supplementary Tables

$243 \mathrm{~S} 4$ and S5). Late $I_{\mathrm{Na}}$, measured as the current integral from 50 to $800 \mathrm{~ms}$ from the beginning

244 of the pulse ${ }^{14}$, was similarly reduced in magnitude (Fig. $7 \mathrm{i}, \mathrm{j}$ and k). This analysis indicates 
bioRxiv preprint doi: https://doi.org/10.1101/813592; this version posted October 21,2019 . The copyright holder for this preprint (which was not certified by peer review) is the author/funder, who has granted bioRxiv a license to display the preprint in perpetuity. It is made available under aCC-BY 4.0 International license.

245 that coregulation via co-knockdown results in quantitatively similar alteration of $I_{\mathrm{Na}, \text { late }}$ and $I_{\mathrm{Kr}}$,

246 which operate together to regulate repolarization ${ }^{15} . I_{\text {to }}$, which does not regulate action

247 potential duration in larger mammals ${ }^{16}$, is unaffected by $h E R G 1 b$ silencing (Fig. 8a, b, c and

$248 \mathrm{~d}$ ), suggesting the coregulation of $I_{\mathrm{Na}}$ and $I_{\mathrm{Kr}}$ reflects their coherent participation in

249 repolarization.

250

251

252 


\section{DISCUSSION}

254 We have demonstrated using diverse and independent approaches the association and coregulation of transcripts encoding ion channels that regulate excitability in cardiomyocytes.

256 By co-immunoprecipitating mRNA transcripts along with their nascent proteins, we have

257 shown that $h E R G$ and SCN5A transcripts associate natively in human ventricular

258 myocardium and iPSC-CMs as well as when heterologously expressed in HEK293 cells.

259 Using smFISH together with immunofluorescence in iPSC-CMs, we demonstrate that the

260 ratio of $h E R G$ and $S C N 5 A$ transcripts is approximately 1:1 despite a range of pool sizes from

261 roughly 5 to 200 molecules per cell. These transcripts colocalize about $25 \%$ of the time, but

262 when considering only those $h E R G$ transcripts undergoing translation, nearly $50 \%$ are

263 associated with SCN5A. When hERG1a or $h E R G 1 b$ transcripts are targeted by shRNA,

$264 S C N 5 A$ levels are reduced by about the same amount. Both peak and late $I_{\mathrm{Na}}$ are

265 correspondingly reduced. Reflecting their coherent roles in the process of cardiac

266 repolarization, the term "microtranslatome" captures the cotranslational properties of this

267 discrete complex comprising functionally related mRNAs and their nascent proteins.

269 What is the functional role of cotranslational association of transcripts? Deutsch and

270 colleagues showed that cotranslational interaction of nascent Kv1.3 N-termini facilitates

271 proper tertiary and quaternary structure required for oligomerization ${ }^{17,18}$. Cotranslational

272 heteromeric association of hERG1a and hERG1b subunits ensures cardiac $I_{\mathrm{kr}}$ has the

273 appropriate biophysical properties and magnitude shaping the normal ventricular action

274 potential. Coordinated protein translation of different channel types could control relative

275 numbers of ion channels involved in electrical signaling events. Such a balance is critical

276 during repolarization, when alterations in $I_{\mathrm{Kr}}$ or late $I_{\mathrm{Na}}$ are known to cause arrhythmias

277 associated with long QT syndrome or Brugada syndrome ${ }^{19-21}$. Indeed, during normal Phase 3

278 repolarization, non-equilibrium gating of sodium channels leads to recovery from inactivation

279 and re-activation of currents substantially larger than the tiny steady-state late $I_{\mathrm{Na}}$ observed

280 under voltage-clamp steps ${ }^{15,22}$. Our observation of roughly equivalent $h E R G 1 a$ and SCN5A 
281 mRNA levels squares with previous reports of fixed channel transcript ratios associated with

282 certain identified crustacean neurons ${ }^{23,24}$. Cotranslating mRNAs in a stoichiometric manner

283 could buffer noise associated with transcription ${ }^{25}$ and render a stable balance of channel

284 protein underlying control of membrane potential.

285

286 These studies raise questions of the mechanism by which transcripts associate. Although

287 hERG1a and hERG1b N-termini interact during translation ${ }^{7}$, association of transcripts does

288 not rely on this interaction: alternate transcripts encoding the proteins interact even when

289 translation of one of the proteins is prevented ${ }^{9}$. In principle, transcripts could associate via

290 complementary base pairing or by tertiary structural interactions as ligand and receptor.

291 Alternatively, they could be linked by one or more RNA binding proteins (RBPs). Because the

292 association and coregulation observed in native heart can be reproduced in HEK293 cells,

293 the same or similar mechanisms are at work in the two systems. More work will be required

294 to discern among possible mechanisms, and to determine the time course with respect to

295 transcription, nuclear export and cytosolic localization of interacting transcripts.

296

297 A mechanism involving RBPs is appealing because it comports with the idea of the "RNA

298 regulon," a term describing a complex of transcripts bound by one or more RBPs ${ }^{26,27}$. RBPs

299 in the yeast Puf family bind large collections of mRNAs to control their localization, stability,

300 translation and decay ${ }^{28,29}$. In mammalian systems, the Nova protein serves to coordinate

301 expression of mRNAs encoding splicing proteins important in synaptic function ${ }^{30}$.

302 Presumably in both cases these proteins interact in multiple regulons (complexes) serving

303 different or related roles. Mata and colleagues isolated individual mRNA species in yeast and

304 showed they associate with other mRNAs encoding functionally related (but nonhomologous)

305 proteins, along with mRNA encoding the RBP itself ${ }^{31}$. Moreover, these mRNAs encoded

306 proteins that formed stable macromolecular complexes ${ }^{32}$. Taking it one step further, Cosker

307 et al. showed that two mRNAs involved in cytoskeletal regulation bind the same RBP to form 
308 a single RNA granule ${ }^{33}$, possibly analogous to the microtranslatome regulating key elements

309 of excitability in the heart reported here.

310

311 A comprehensive analysis of the microtranslatome's components will require RNA-seq at a

312 level of multiplexing that ensures sufficient statistical power in the face of potentially reduced

313 complexity of the RNA-IP samples. These efforts will necessarily be followed by validation

314 through complementary approaches such as RNAi and smFISH to confirm their identity

315 within the microtranslatome.

316

317 One of the more curious findings of our study is the coordinate knockdown of different

318 mRNAs in the complex by shRNAs targeted to only one of the mRNA species. The

319 mechanism by which multiple mRNA species may be simultaneously regulated is not clear.

320 shRNAs silence gene expression by producing an antisense (guide) strand that directs the

321 RNA-induced silencing complex (RISC) to cleave, or suppress translation of, the target

$322 \mathrm{mRNA}^{34,35}$. Since hERG shRNA has no off-target effect on SCN5A mRNA expressed

323 heterologously in HEK293 cells, we assume there is insufficient complementarity for a direct

324 action. Perhaps by proximity to RISC, translation of the nontargeted mRNA is also disrupted,

325 but to our knowledge no current evidence is available to support this idea. A transcriptional

326 feedback mechanism seems unlikely given that co-knockdown can occur with plasmids

327 transiently expressed from engineered promoters and not integrated into the genome of

328 HEK293 cells. It is also important to note that it is unknown whether SCN5A is the only

329 sodium channel transcript coregulated by $h E R G$ knockdown. In principle, transcripts

330 encoding other sodium channels implicated in late $I_{\mathrm{Na}}$, such as Nav1.8 ${ }^{36,37}$, could also be

331 affected, as could transcripts encoding auxiliary subunits associated with Nav1.5

332

333 Whether disrupting the integrity of these complexes gives rise to some of the many

334 arrhythmias not attributable to mutations in ion channel genes per se remains to be

335 determined. Although the coregulation of inward $I_{\mathrm{Na}}$ and outward $I_{\mathrm{Kr}}$ shown in this study may 
336 suggest a compensatory mechanism, in a previous study we showed that selective

337 knockdown of $h E R G 1 b$ prolongs action potential duration and enhances variability, both

338 cellular markers of proarrhythmia ${ }^{10}$. Perhaps in the absence of co-regulation the effects

339 would be more deleterious. Jalife and colleagues have introduced the concept of the

340 "channelosome," a macromolecular protein complex mediating a physiological action.

341 Interestingly, Nav1.5 and Kir2.1, which regulates resting and diastolic membrane potential,

342 exhibit compensatory changes when the levels of either are genetically manipulated ${ }^{39}$. In this

343 case, the effect seems to be on stability of the nontargeted channel proteins, which form a

344 complex together with SAP97, and not on mRNA levels ${ }^{40}$. We do not yet know whether the

345 complex of transcripts we have studied encodes a similarly stable macromolecular complex,

346 or perhaps ensures appropriate ratios of channels distributed independently at the

347 membrane. Based on current evidence, we propose that the microtranslatome of associated

348 transcripts is a novel mechanism governing the quantitative expression of multiple ion

349 channel types and thus the balance of excitability in the cardiomyocyte.

350

351

352

353

354

355 


\section{Cell culture, plasmids and transfection}

359 HEK293 cells were cultured under standard conditions $\left(37^{\circ} \mathrm{C}, 5 \% \mathrm{CO}_{2}\right)$ in DMEM medium

360 (Gibco) supplemented with 10\% Fetal Bovine Serum (FBS, Gibco). iPSC-CM (iCell ${ }^{\circledR}$, Cellular

361 Dynamics International) were plated and cultured following manufacturer's instructions.

362 ShRNA sequences specific for hERG1a 5'-GCGCAGCGGCTTGCTCAACTCCACCTCGG-3'

363 and its control 5'-GCACTACCAGAGCTAACTCAGATAGTACT-3' were provided by Origene

364 into a pGFP-V-RS vector. shRNA specific for hERG1b 5'-CCACAACCACCCTGGCTTCAT-3'

365 and its respective control were purchased from Sigma-Aldrich. For heterologous expression,

366 hERG1a (NM_000238) and hERG1b (NM_172057) sequences were cloned into pcDNA3.1.

367 Transient transfections were performed using $2.5 \mu \mathrm{l} / \mathrm{ml} \mathrm{Lipofectamin}^{\mathrm{TM}} 2000$ (Thermofisher)

368 with $2 \mu \mathrm{g} / \mathrm{ml}$ plasmid. Cells were collected for further analysis $48 \mathrm{~h}$ after transfection. When

369 needed, a second transfection was performed $24 \mathrm{~h}$ after the first one with either hERG1a or

370 hERG1b shRNA and the corresponding scrambled shRNA as a control. Cells were then

371 collected for experiments $48 \mathrm{~h}$ after last transfection.

\section{Antibodies}

374 Rabbit anti-hERG1a (\#12889 from Cell Signaling, 1:100), rabbit anti-hERG1b (\#ALX-215-051

375 from Enzo, 1:100), rabbit anti-pan hERG (\#ALX-215-049 from Enzo, 1:3000), rabbit anti

376 Nav1.5 (\#ASC-005 from Alomone or \#D9J7S from Cell signaling, 1:500), were used for

377 immunofluorescence, western blot or RNA-IP experiments. Alexa 647 goat anti-rabbit, Alexa

378488 goat anti-rabbit or Alexa 488 donkey anti-mouse were employed for indirect

379 immunofluorescence or immunoblotting experiments (Thermofisher; 1:1000).

380

381 RNA isolation and semi-quantitative real-time PCR

382 RNA isolation and purification were achieved using TriZol reagent (Life Technologies) and

383 RNeasy Mini Kit (Qiagen). RT-qPCR experiments were performed using a TaqMan Gene 
384 Expression Assay (Life Technologies) and mRNA expression levels were calculated using

385 the $2^{-\Delta \Delta C t}$ cycle threshold method. All data were normalized to mRNA level of $\beta$-actin

386 housekeeping genes. Because iPSC-CMs are subject to inherent biological variability, we

387 used a standardization procedure to normalize the independent biological replicates as

388 previously described ${ }^{41}$. Briefly, a log transformation of the normalized relative expression

389 gene level was performed, followed by mean centering and autoscaling of the data set.

390 Results are expressed as average and 95\% confidence intervals. Primers were purchased

391 from Invitrogen (hERG1a: Hs00165120_m1; hERG1b: Hs04234675_m1; SCN5A:

392 Hs00165693_m1; RYR2: Hs00892883_m1; and $\beta$-actin: Hs01060665_g1).

393

394 Immunofluorescence

395 For immunofluorescence studies, iPSC-CMs were grown on gelatin-coated coverslips, rinsed

396 in PBS three times and fixed in 4\% paraformaldehyde for 10 minutes at room temperature.

397 Following fixation, cells were incubated $1 \mathrm{~h}$ at room temperature with a solution containing

$3980.5 \%$ triton $100 \mathrm{X}$ for permeabilization and $1 \%$ bovine serum albumin along with $10 \%$ serums

399 (secondary antibodies species) diluted in PBS to saturate samples and limit nonspecific

400 binding. Cells were then processed for indirect immunofluorescence using a combination of

401 primary and secondary antibodies (see antibodies section above). Cells were washed three

402 times with PBS, incubated with DAPI to counterstain nuclei and mounted with Vectafield

403 mounting medium.

404

405 Single-molecule fluorescence in situ hybridization (smFISH)

406 FISH was performed using Stellaris ${ }^{\circledR}$ probe sets, which comprised up to 48 oligonucleotides

407 designed to selectively bind in series the targeted transcripts. Probes were designed using

408 the StellarisTM Probe Designer by LGC Biosearch Technologies with the following

409 parameters: masking level: 5, oligo length: 20 nucleotides, and minimum spacing length: 2

410 nucleotides. Oligonucleotides were labeled with TAMRA or Quasar ${ }^{\circledR} 670$ dyes for detection of

$411 S C N 5 A$ and $h E R G$ respectively. 48 oligonucleotides were designed for SCN5A, RyR2 and 
412 GAPDH and 35 for the specific N-terminal sequence of $h E R G 1 a$. Sequences for all probes

413 are provided in Supplementary Table 1. FISH was performed on iPSC-CMs according the

414 manufacturer's protocol. Briefly, fixation was performed by adding paraformaldehyde to a

415 final concentration of $4 \%$ (32\% solution, EM grade; Electron Microscopy Science) followed by

416 a hybridization step for at least $4 \mathrm{~h}$ at $37^{\circ} \mathrm{C}$ in a buffer containing a final concentration of 125

$417 \mathrm{nM}$ probes and 10\% formamide (Stellaris hybridization buffer). Cells were washed for $30 \mathrm{~min}$

418 (Stellaris washing buffer $\mathrm{A}$ ) before incubation for $30 \mathrm{~min}$ at $37^{\circ} \mathrm{C}$ with DAPI to counterstain

419 the nuclei. A final washing step was performed (Stellaris washing buffer B) and coverglasses

420 were mounted onto the slide with Vectashield mounting medium.

421 Digital images were acquired using a 63X objective on a Leica DMi8 AFC Inverted wide-field

422 fluorescence microscope. Z-sections were acquired at $200 \mathrm{~nm}$ intervals. Image pixel size:

$423 \mathrm{XY}, 106.3 \mathrm{~nm}$. Image post-treatments were performed using ImageJ software (NIH). Briefly,

424 a maximum projection was performed before background subtraction and images were

425 filtered using a Gaussian blur filter to improve the signal/noise ratio and facilitate spot

426 detection. Spot detection and colocalization was performed using the plugin ComDet on

427 Image ${ }^{42,43}$.

428 FISHQUANT was used as a second method for spot detection and gave similar values.

429 Briefly, background was substracted using a Laplacian of Gaussian (LoG) and spots were fit

430 to a three-dimensional (3D) Gaussian to determine the coordinates of the mRNA molecules.

431 Intensity and width of the 3D Gaussian were thresholded to exclude non-specific signal ${ }^{11,12}$.

432 To evaluate the number of mRNA molecules, the total fluorescence intensity of smFISH

433 signals was fitted with the sum of Gaussian functions (see equation below) to determine the

434 mean intensity of a single mRNA.

435

$$
y=y_{0}+\frac{A}{w \sqrt{\frac{\pi}{2}}} e^{-2\left(\frac{x-x c}{w}\right)^{2}}
$$




\section{Statistical analysis of smFISH and IF}

439 For the purpose of our statistical calculations, we assumed that the protein and mRNA

440 signals were circular. The following formulas were used to calculate the expected number of

441 mRNAs $\left(E_{m}\right)$ that would interact based on chance alone for each association criteria:

$$
E_{m}=\frac{N_{m 1} N_{m 2}\left(2 \pi r^{2}-I\right)}{A}
$$

444 where $\mathrm{N}_{\mathrm{m} 1}$ is the total number of $\mathrm{mRNA}$ in one channel, $\mathrm{N}_{\mathrm{m} 2}$ is the total number of $\mathrm{mRNA}$ in 445 the second channel, $r$ is the average radius of mRNA spots (in $\mathrm{nm}$ ), I is the intersection

446 between particles $\left(\mathrm{nm}^{2}\right)$, and $A$ is the total area of the region analyzed (in $\mathrm{nm}^{2}$ ). As the 447 distance between particles is increased, the number of expected associated mRNAs will 448 increase since more mRNAs will be considered associated. We used criteria with different 449 stringency in the first set of experiments (from 1 pixel to 4 pixels distance between spots) and 450 considered the 2 pixels distance between spots physiologically relevant for triple association 451 analysis and co-knockdown experiments.

452 To test the significance of triple associations between hERG1a mRNA, SCN5A mRNA and hERG1a protein, the following formula was used:

454

$$
E_{p}=\frac{N_{p} E_{m}\left(\pi r^{2}-I\right)}{A}
$$

456 where $N_{p}$ is the total number of proteins, $E_{m}$ is the expected number of mRNA that would

457 interact based on chance alone as calculated above. For each association criteria, the

458 intersection between particles was calculated using the following equation:

$$
I=2 r^{2} \cos ^{-1}\left(\frac{d}{2 r}\right)-\frac{1}{2} d\left(\sqrt{4 r^{2}-d^{2}}\right)
$$


Correlation analysis

463 mRNA numbers were plotted against each other from different combinations of smFISH

464 signals as scatter plots. Then Pearson's and Spearman's correlation coefficients were

465 evaluated to assess correlation between considered mRNA species.

466 The following equation was used to calculate Pearson's coefficient $R$ and determine the

467 coefficient of determination $\mathrm{R}^{2}$ from the mRNA pairs $x_{i}, y_{i}$ :

$$
R=\frac{\operatorname{Cov}\left(x_{i}, y_{i}\right)}{\sigma_{x_{i}}-\sigma_{y_{i}}}
$$

468 where $\operatorname{Cov}\left(X_{i}, Y_{i}\right)$ is the covariance of the values and $\sigma_{x_{i}}-\sigma_{y_{i}}$ is the difference between the 469 standard deviation of the values. Significance was determine using a F test.

471 The Spearman's coefficient $\rho$ was determined on ranked values $X_{i}$ and $Y_{i}$ using the following 472 equation:

$$
\rho=\frac{\operatorname{Cov}\left(X_{i}, Y_{i}\right)}{\sigma_{X_{i}}-\sigma_{Y_{i}}}
$$

473 where $\operatorname{Cov}\left(X_{i}, Y_{i}\right)$ is the covariance of the rank values and $\sigma_{X_{i}}-\sigma_{Y_{i}}$ is the difference between

474 the standard deviation of the ranked values. Significance was determine using two-tailed 475 probability test.

478 RNA-IP (RNA-immunoprecipitation)

479 Ribonucleoprotein (RNP) complexes were isolated with a RiboCluster Profiler TM RIP-Assay 480 Kit (Medical \& Biological Sciences) using protein-specific antibodies and Ab-immobilized A/G agarose beads. After formation of the RNP/beads complex, we used guanidine hydrochloride

482 solution to dissociate beads from RNP complexes. Finally, target RNAs were analyzed using 483 RT-PCR. 


\section{Electrophysiological measurements}

486 Patch clamp under whole-cell configuration was used to record all ionic currents. $I_{\mathrm{kr}}$ and

$487 I_{\mathrm{Na}, \text { late }}$ were recorded at physiological temperatures $\left(37^{\circ} \mathrm{C}\right)$, while $I_{\mathrm{Na}}$ was recorded at room

488 temperature $\left(22^{\circ} \mathrm{C}\right)$ using an Axon 200B amplifier and Clampex Software (Molecular

489 Devices). Glass pipettes with a resistance of $2.5-5 \mathrm{M} \Omega$ measured with physiological

490 solutions (below) were pulled using an automatic P-97 Micropipette Puller system (Sutter

491 Instruments).

492

493 To record steady state and tail $I_{\mathrm{Kr}}$, cells were continuously perfused with an external solution

494 containing (in $\mathrm{mM}$ ): $\mathrm{NaCl} 150, \mathrm{KCl} 5.4, \mathrm{CaCl}_{2} 1.8, \mathrm{MgCl}_{2}$ 1, Glucose 15, HEPES 15, Na-

495 pyruvate 1, and the $\mathrm{pH}$ was adjusted to 7.4 with $\mathrm{NaOH}$. Pipettes were filled with an internal

496 solution containing (in $\mathrm{mM}$ ): $\mathrm{NaCl} 5, \mathrm{KCl} 150, \mathrm{CaCl}_{2}$ 2, EGTA 5, HEPES 10, Mg-ATP 5, and

497 the $\mathrm{pH}$ was adjusted to 7.3 with $\mathrm{NaOH}$. The voltage protocol for $I_{\mathrm{Kr}}$ was completed at

498 physiological temperature $\left(37^{\circ} \mathrm{C}\right)$ and determined as an $\mathrm{E}-4031(2 \mu \mathrm{M})$ sensitive current.

499 Cells were recorded using a holding potential of $-50 \mathrm{mV}$, followed by a pulse at $-40 \mathrm{mV}$ to

500 inactivate sodium channels, then $3-$ second depolarizing steps (from -50 to $+30 \mathrm{mV}$ in $10 \mathrm{mV}$

501 increments) to activate $\mathrm{hERG}$ channels and finally to $-40 \mathrm{mV}$ for 6 seconds. Steady-state $I_{\mathrm{kr}}$

502 was measured as the $5 \mathrm{~ms}$ average current at the end of the depolarizing steps. Tail currents

503 were measured following the return to $-40 \mathrm{mV}$.

504 To record $I_{\mathrm{Na}}$, cells were perfused with an external solution containing (in $\mathrm{mM}$ ): $\mathrm{NaCl} 50$,

505 Tetraethylammonium (TEA) methanesulfonate 90, $\mathrm{CaCl}_{2} 2, \mathrm{MgCl}_{2}$ 1, Glucose 10, HEPES 10,

506 Na-pyruvate 1, Nifedipine $10 \mu \mathrm{M}$, and pH adjusted to 7.4 with TEA-OH. Micropipettes were

507 filled with an internal solution containing (in $\mathrm{mM}$ ): $\mathrm{NaCl} 10, \mathrm{CaCl}_{2} 2, \mathrm{CsCl} 135, \mathrm{EGTA} 5$,

508 HEPES 10, Mg-ATP 5, and pH was adjusted to 7.3 with $\mathrm{CsOH}$.

$509 I_{\mathrm{Na}}$ activation was investigated by applying pulses between -140 and $+20 \mathrm{mV}$ in $10 \mathrm{mV}$

510 increments from a holding potential of $-120 \mathrm{mV}$. To measure inactivation of sodium channels, 
511 conditioning pulses from -140 to $+20 \mathrm{mV}$ in $10 \mathrm{mV}$ increments were applied from a holding

512 potential of $-120 \mathrm{mV}$ following by a test pulse to $-20 \mathrm{mV}$.

513 To record $I_{\mathrm{Na} \text {,late, }}$, cells were perfused with an external solution containing (in $\mathrm{mM}$ ): $140, \mathrm{CsCl}$

$5145.4, \mathrm{CaCl}_{2} 1.8, \mathrm{MgCl}_{2}$ 2, HEPES 5, Nifedipine $10 \mu \mathrm{M}$, and $\mathrm{pH}$ was adjusted to 7.3 with $\mathrm{NaOH}$.

515 Pipette were filled with an internal solution containing (in $\mathrm{mM}$ ): $\mathrm{NaCl} 5, \mathrm{CsCl} 133, \mathrm{Mg}-\mathrm{ATP}$

5162 , TEA 20, EGTA 10, HEPES 5, and $\mathrm{pH}$ was adjusted to 7.33 with $\mathrm{CsOH}$. $I_{\mathrm{Na} \text {,late }}$ was

517 measured by applying an $800 \mathrm{~ms}$ single pulse to $-30 \mathrm{mV}$ from a holding potential of $-120 \mathrm{mV}$.

518 The mean current was measured at the last $200 \mathrm{~ms}$ of the pulse. An external solution

519 containing $30 \mu \mathrm{M}$ TTX was perfused after the first pulse to determine if the current was due

520 to the activity of sodium channels.

521 To record $I_{\text {to }}$, cells were continuously perfused with an external solution containing (in $\mathrm{mM}$ ):

$522 \mathrm{NaCl} 150, \mathrm{KCl} 5.4, \mathrm{CaCl}_{2}$ 1.8, $\mathrm{MgCl}_{2}$ 1, Glucose 15, HEPES 15, Na-pyruvate 1, E4031 2,

$523 \mathrm{CdCl}_{2} 0.5$ and the $\mathrm{pH}$ was adjusted to 7.4 with $\mathrm{NaOH}$. Pipettes were filled with an internal

524 solution containing (in $\mathrm{mM}$ ): $\mathrm{NaCl} 5, \mathrm{KCl} 150, \mathrm{CaCl}_{2} 2$, EGTA 5, HEPES 10, Mg-ATP 5, and

525 the $\mathrm{pH}$ was adjusted to 7.3 with $\mathrm{NaOH}$.

526 Both activation (for $I_{\mathrm{Kr}}$, Ito and $I_{\mathrm{Na}}$ ) and inactivation (for $I_{\mathrm{Na}}$ ) were fitted to Boltzmann equations

527 (Equations (1) and (2), respectively) and voltage dependence parameters were obtained.

$$
I(V)=\frac{\left(V-V_{r e v}\right) G_{\max }}{1+e^{\frac{\left(V-V_{1 / 2}\right)}{k}}}
$$

\section{Acknowledgements}

535 Research reported in this publication was supported by the National Heart, Lung and Blood

536 Institute of the National Institutes of Health R01HL131403. The authors thank Dr. Peter

537 Mohler of the Dorothy Davis Heart and Lung Institute for heart samples and Drs. Barry 
541 manuscript.

\section{Author Contributions}

543 Experiments were conceived and designed by C.A.E, E.R.-P., F.L. and G.A.R. C.A.E. and

544 M.B.J. carried out single molecule FISH experiments. F.L. and J.J.K. conducted RNA-IP and

545 knock-down experiments. E.B.R-P. and D.K.J. performed electrophysiology experiments.

546 C.A.E. and G.A.R. wrote the manuscript and all authors provided critical feedback to the final

547 version.

\section{Data Availability}

550 The source data corresponding to Figures 1b, 2b, 2c, 2d, 2e, 3b, 3d, 4b, 4c, 4e, 5b, 5c, 5d, $5516 \mathrm{~b}, 6 \mathrm{c}, 6 \mathrm{~d}, 7 \mathrm{a}, 7 \mathrm{~b}, 7 \mathrm{~d}, 7 \mathrm{e}, 7 \mathrm{~g}, 7 \mathrm{~h}, 7 \mathrm{j}, 7 \mathrm{k}, 8 \mathrm{a}, 8 \mathrm{~b}, 8 \mathrm{~d}$ and Supplementary Figures S1, S3a, 552 S3b, S3c, S4a, S4b, S5a, S5b, S6b, S7b, S7c. Raw files images and other data supporting 553 the findings of this study are available upon request.

\section{Reference list}

557 1. Roden, D. M. Predicting drug-induced QT prolongation and torsades de pointes. J. 558 Physiol. 594, 2459-2468 (2016).

559 2. Sanguinetti, M. C. \& Jurkiewicz, N. K. Two components of cardiac delayed rectifier

$560 \mathrm{~K}+$ current. Differential sensitivity to block by class III antiarrhythmic agents. J. Gen.

561 Physiol. 96, 195-215 (1990).

562 3. Sanguinetti, M. C., Jiang, C., Curran, M. E. \& Keating, M. T. A mechanistic link

563 between an inherited and an acquired cardiac arrhythmia: HERG encodes the IKr potassium 564 channel. Cell 81, 299-307 (1995).

565 4. Trudeau, M. C., Warmke, J. W., Ganetzky, B. \& Robertson, G. A. HERG, a human

566 inward rectifier in the voltage-gated potassium channel family. Science 269, 92-95 (1995).

5675 5 Sale, H. et al. Physiological properties of hERG 1a/1b heteromeric currents and a

568 hERG 1b-specific mutation associated with Long-QT syndrome. Circ. Res. 103, e81-95

569 (2008).

570 6. Jones, E. M. C., Roti, E. C. R., Wang, J., Delfosse, S. A. \& Robertson, G. A. Cardiac 
571 IKr Channels Minimally Comprise hERG 1a and 1b Subunits. J. Biol. Chem. 279, 44690$57244694(2004)$.

$5737 . \quad$ Phartiyal, P., Jones, E. M. C. \& Robertson, G. A. Heteromeric Assembly of Human

574 Ether-à-go-go-related Gene (hERG) 1a/1b Channels Occurs Cotranslationally via N-terminal

575 Interactions. J. Biol. Chem. 282, 9874-9882 (2007).

576 8. McNally, B. A., Pendon, Z. D. \& Trudeau, M. C. hERG1a and hERG1b potassium

577 channel subunits directly interact and preferentially form heteromeric channels. J. Biol. Chem.

578 292, 21548-21557 (2017).

579 9. Liu, F., Jones, D. K., de Lange, W. J. \& Robertson, G. A. Cotranslational association

580 of mRNA encoding subunits of heteromeric ion channels. Proc. Natl. Acad. Sci. U. S. A. 113,

581 4859-4864 (2016).

582 10. Jones, D. K. et al. hERG $1 \mathrm{~b}$ is critical for human cardiac repolarization. Proc. Natl.

583 Acad. Sci. 111, 18073-18077 (2014).

584 11. Raj, A., van den Bogaard, P., Rifkin, S. A., van Oudenaarden, A. \& Tyagi, S. Imaging

585 individual mRNA molecules using multiple singly labeled probes. Nat. Methods 5, 877-879

586 (2008).

587 12. Femino, A. M., Fay, F. S., Fogarty, K. \& Singer, R. H. Visualization of Single RNA

588 Transcripts in Situ. Science 280, 585-590 (1998).

589 13. Azzam, M. E. \& Algranati, I. D. Mechanism of Puromycin Action: Fate of Ribosomes

590 after Release of Nascent Protein Chains from Polysomes. Proc. Natl. Acad. Sci. 70, 3866-

5913869 (1973).

592 14. Glynn, P. et al. Voltage-Gated Sodium Channel Phosphorylation at Ser571 Regulates

593 Late Current, Arrhythmia, and Cardiac Function In Vivo. Circulation 132, 567-577 (2015).

594 15. Banyasz, T., Horvath, B., Jian, Z., Izu, L. T. \& Chen-Izu, Y. Sequential dissection of

595 multiple ionic currents in single cardiac myocytes under action potential-clamp. J. Mol. Cell.

596 Cardiol. 50, 578-581 (2011).

597 16. Sun, X. \& Wang, H.-S. Role of the transient outward current (Ito) in shaping canine

598 ventricular action potential - a dynamic clamp study. J. Physiol. 564, 411-419 (2005).

599 17. Tu, L. \& Deutsch, C. Evidence for dimerization of dimers in K+ channel assembly.

600 Biophys. J. 76, 2004-2017 (1999).

601 18. Robinson, J. M. \& Deutsch, C. Coupled tertiary folding and oligomerization of the T1

602 domain of Kv channels. Neuron 45, 223-232 (2005).

603 19. Rook, M. B. et al. Human SCN5 A gene mutations alter cardiac sodium channel

604 kinetics and are associated with the Brugada syndrome. Cardiovasc. Res. 44, 507-517 (1999).

605 20. Bezzina, C. et al. A single $\mathrm{Na}(+)$ channel mutation causing both long-QT and Brugada

606 syndromes. Circ. Res. 85, 1206-1213 (1999).

607 21. Bennett, P. B., Yazawa, K., Makita, N. \& George, A. L. Molecular mechanism for an

608 inherited cardiac arrhythmia. Nature 376, 683 (1995).

609 22. Clancy, C. E., Tateyama, M., Liu, H., Wehrens, X. H. T. \& Kass, R. S. Non-

610 equilibrium gating in cardiac $\mathrm{Na}+$ channels: an original mechanism of arrhythmia. Circulation

611 107, 2233-2237 (2003).

612 23. Schulz, D. J., Goaillard, J.-M. \& Marder, E. E. Quantitative expression profiling of

613 identified neurons reveals cell-specific constraints on highly variable levels of gene

614 expression. Proc. Natl. Acad. Sci. U. S. A. 104, 13187-13191 (2007).

615 24. Schulz, D. J., Goaillard, J.-M. \& Marder, E. Variable channel expression in identified

616 single and electrically coupled neurons in different animals. Nat. Neurosci. 9, 356-362

617 (2006).

618 25. Dar, R. D. et al. Transcriptional burst frequency and burst size are equally modulated

619 across the human genome. Proc. Natl. Acad. Sci. U. S. A. 109, 17454-17459 (2012).

620 26. Brown, V. et al. Microarray identification of FMRP-associated brain mRNAs and 
621 altered mRNA translational profiles in fragile X syndrome. Cell 107, 477-487 (2001).

622 27. Keene, J. D. \& Tenenbaum, S. A. Eukaryotic mRNPs May Represent

623 Posttranscriptional Operons. Mol. Cell 9, 1161-1167 (2002).

624 28. Gerber, A. P., Herschlag, D. \& Brown, P. O. Extensive Association of Functionally

625 and Cytotopically Related mRNAs with Puf Family RNA-Binding Proteins in Yeast. PLoS

626 Biol. 2, (2004).

627 29. García-Rodríguez, L. J., Gay, A. C. \& Pon, L. A. Puf3p, a Pumilio family RNA

628 binding protein, localizes to mitochondria and regulates mitochondrial biogenesis and motility

629 in budding yeast. J. Cell Biol. 176, 197-207 (2007).

630 30. Ule, J. et al. CLIP Identifies Nova-Regulated RNA Networks in the Brain. Science

$631302,1212-1215$ (2003).

632 31. Duncan, C. D. S. \& Mata, J. Widespread Cotranslational Formation of Protein

633 Complexes. PLoS Genet. 7, (2011).

634 32. Duncan, C. D. \& Mata, J. Cotranslational protein-RNA associations predict protein-

635 protein interactions. BMC Genomics 15, 298 (2014).

636 33. Cosker, K. E., Fenstermacher, S. J., Pazyra-Murphy, M. F., Elliott, H. L. \& Segal, R.

637 A. The RNA-binding protein SFPQ orchestrates an RNA regulon to promote axon viability.

638 Nat. Neurosci. 19, 690-696 (2016).

639 34. Petersen, C. P., Bordeleau, M.-E., Pelletier, J. \& Sharp, P. A. Short RNAs repress

640 translation after initiation in mammalian cells. Mol. Cell 21, 533-542 (2006).

641 35. Maroney, P. A., Yu, Y., Fisher, J. \& Nilsen, T. W. Evidence that microRNAs are

642 associated with translating messenger RNAs in human cells. Nat. Struct. Mol. Biol. 13, 1102-

6431107 (2006).

644 36. Yang, T. et al. Blocking Scn10a channels in heart reduces late sodium current and is

645 antiarrhythmic. Circ. Res. 111, 322-332 (2012).

646 37. Macri, V. et al. Common Coding Variants in SCN10A Are Associated With the

647 Nav1.8 Late Current and Cardiac Conduction. Circ. Genomic Precis. Med. 11, e001663

648 (2018).

64938 Isom, L. L., De Jongh, K. S. \& Catterall, W. A. Auxiliary subunits of voltage-gated

650 ion channels. Neuron 12, 1183-1194 (1994).

651 39. Milstein, M. L. et al. Dynamic reciprocity of sodium and potassium channel

652 expression in a macromolecular complex controls cardiac excitability and arrhythmia. Proc.

653 Natl. Acad. Sci. U. S. A. 109, E2134-2143 (2012).

654 40. Matamoros, M. et al. Nav1.5 N-terminal domain binding to $\alpha 1$-syntrophin increases

655 membrane density of human Kir2.1, Kir2.2 and Nav1.5 channels. Cardiovasc. Res. 110, 279-

656290 (2016).

657 41. Willems, E., Leyns, L. \& Vandesompele, J. Standardization of real-time PCR gene

658 expression data from independent biological replicates. Anal. Biochem. 379, 127-129 (2008).

659 42. Chang, L., Shav-Tal, Y., Trcek, T., Singer, R. H. \& Goldman, R. D. Assembling an

660 intermediate filament network by dynamic cotranslation. J. Cell Biol. 172, 747-758 (2006).

661 43. Hoffman, D. B., Pearson, C. G., Yen, T. J., Howell, B. J. \& Salmon, E. D.

662 Microtubule-dependent Changes in Assembly of Microtubule Motor Proteins and Mitotic

663 Spindle Checkpoint Proteins at PtK1 Kinetochores. Mol. Biol. Cell 12, 1995-2009 (2001).

664

665

666 
a

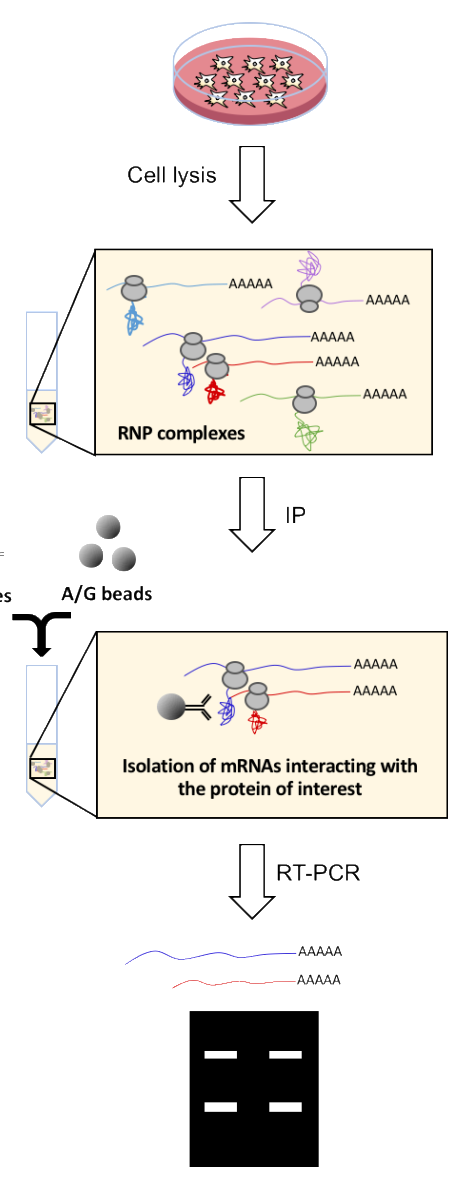

b

RNA-IP

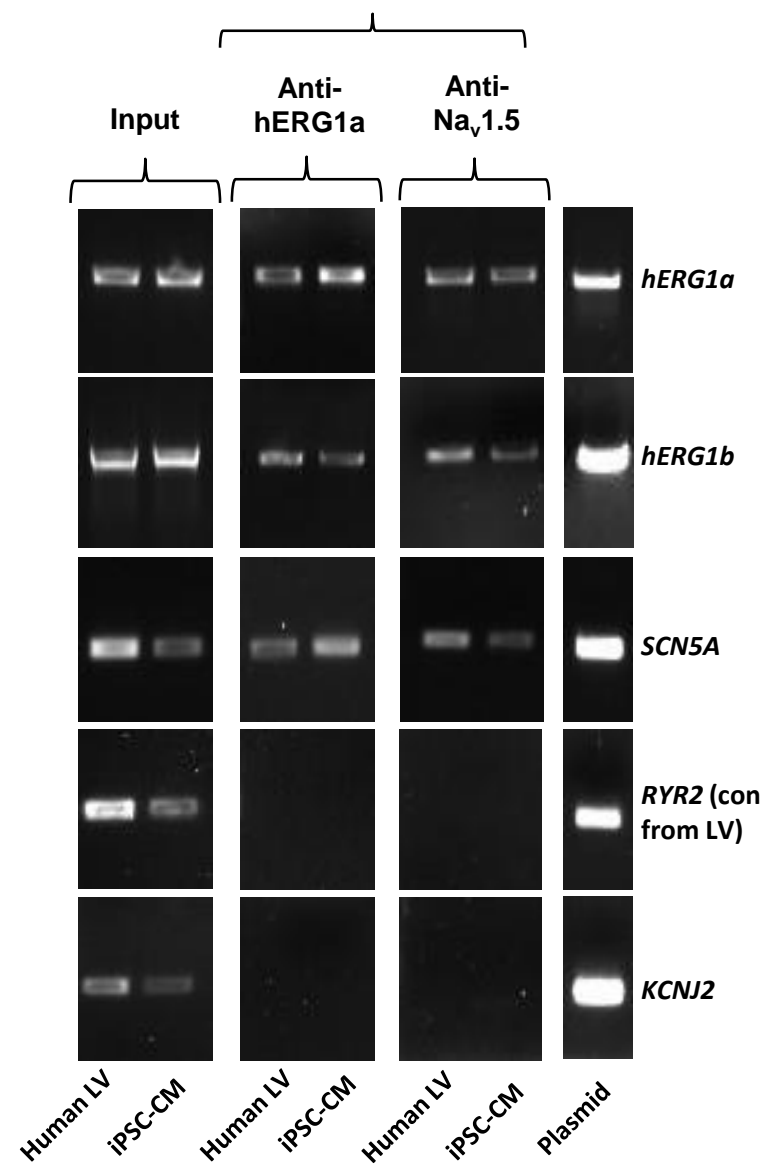

Figure 1: Complex of ion channel transcripts with nascent proteins. a, Scheme of the RNA-IP protocol in which channel-specific antibodies are used to pull down nascent proteins and associated transcripts. RNP: ribonucleoprotein. b, Lanes 1 and 2, RT-PCR products from input lysate of human left ventricle (LV), and iPSC-CM. Lanes 3-16 shows the corresponding RNA-IP's using an anti-hERG1a or anti-Na 1.5 antibodies; Lane 7 shows the control (+) and represents signal amplified from purified plasmid template. Similar results were obtained in at least 3 independent experiments. ( $N=5$ for antihERG1a and N=3 for anti-Nav1.5 using human LV and iPSC-CMs). 
a

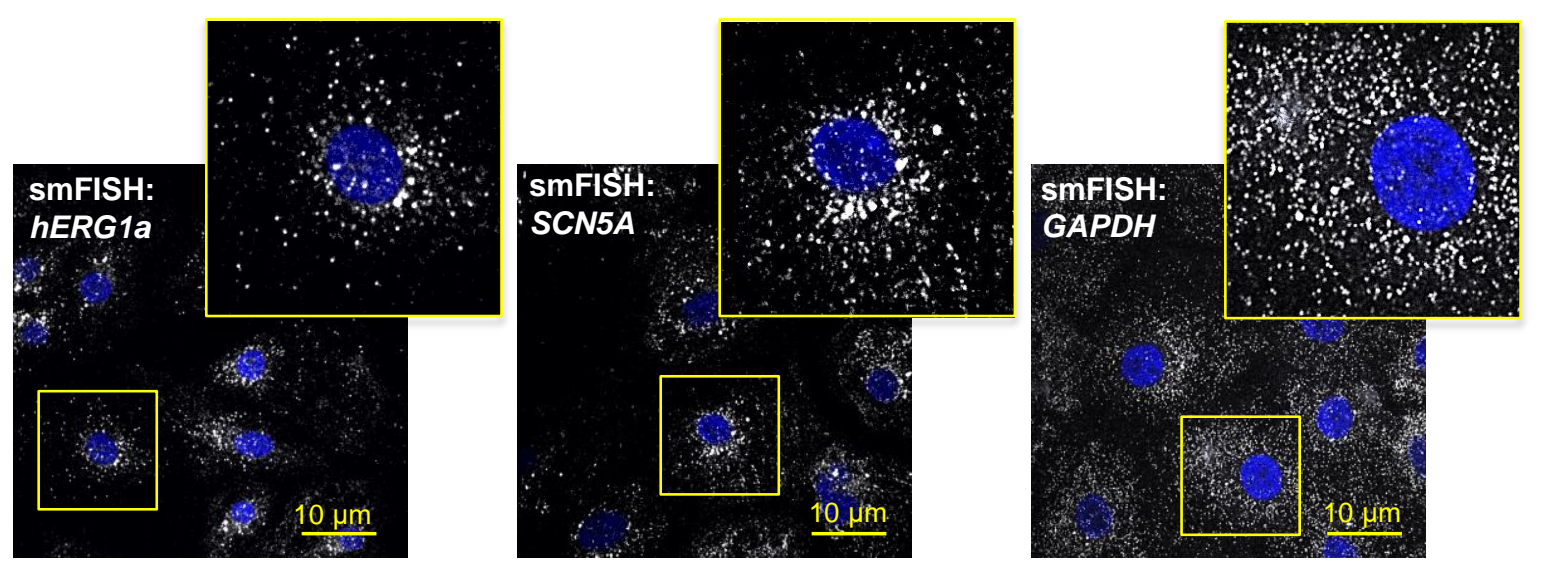

b

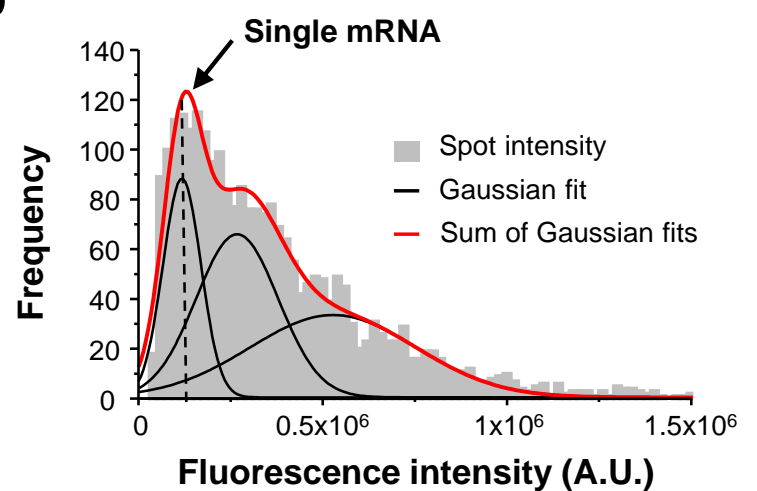

d

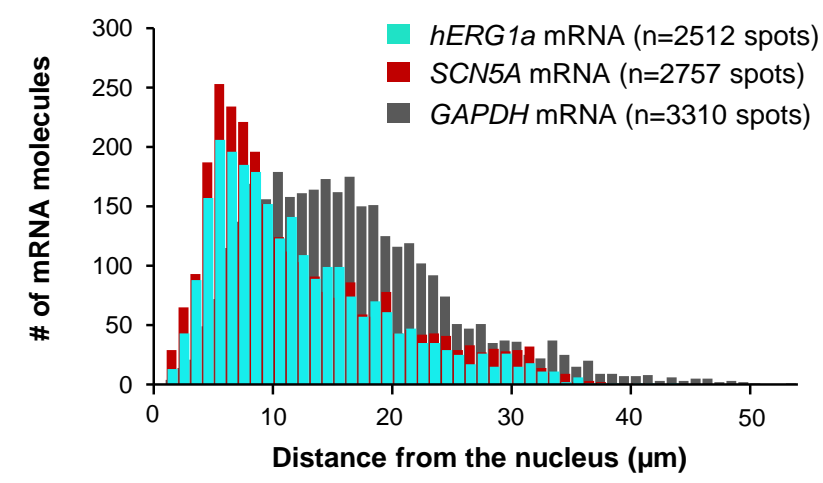

C

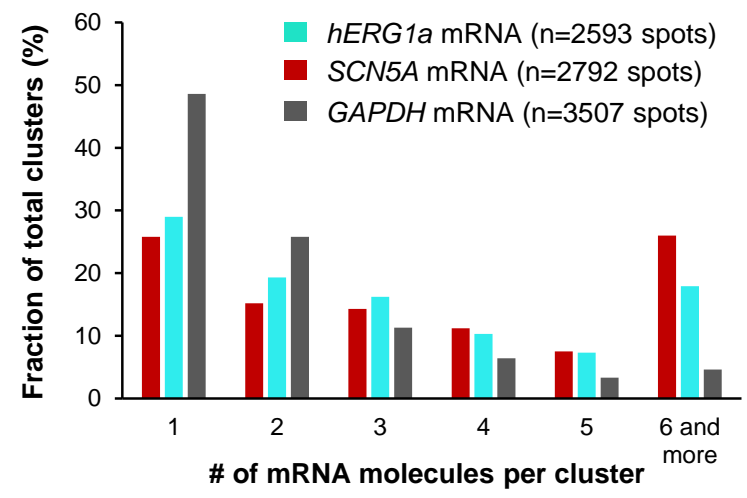

e

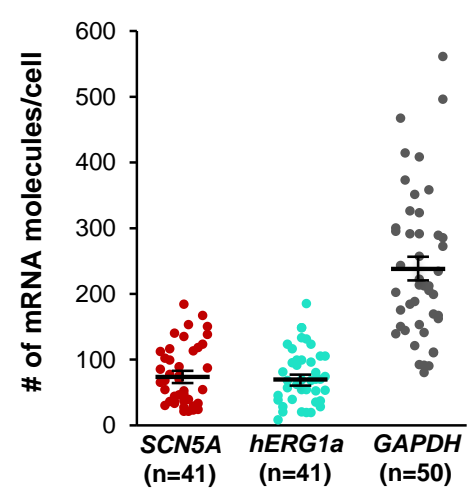

Figure 2: Quantitative description of single hERG1a and SCN5A transcripts and their distribution in iPSC-CMs. a, Representative confocal images and enlargement (outlined in yellow) of iPSC-CMs subjected to the smFISH protocol. $\mathbf{b}$, By fitting the intensity histogram of smFISH signals ( $n=2611$ spots) to the sum of Gaussian functions (red line), the typical intensity corresponding to a single mRNA molecule (vertical dashed line) was extracted. c, The distribution of the number of mRNA molecules associated in clusters for each transcript evaluated by smFISH. d, Histogram showing the cytoplasmic distribution of mRNA signals with distance from the nucleus. e, The number of mRNAs detected per cell was plotted for SCN5A, hERG1a and GAPDH (lines represent mean \pm SE). 
a
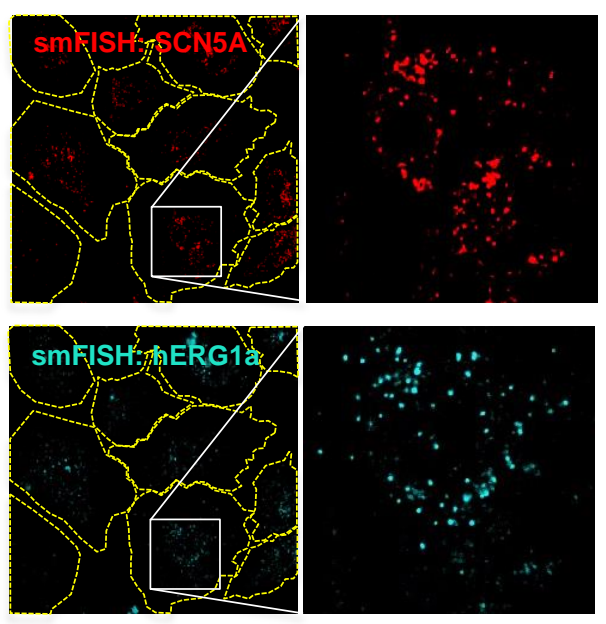

C
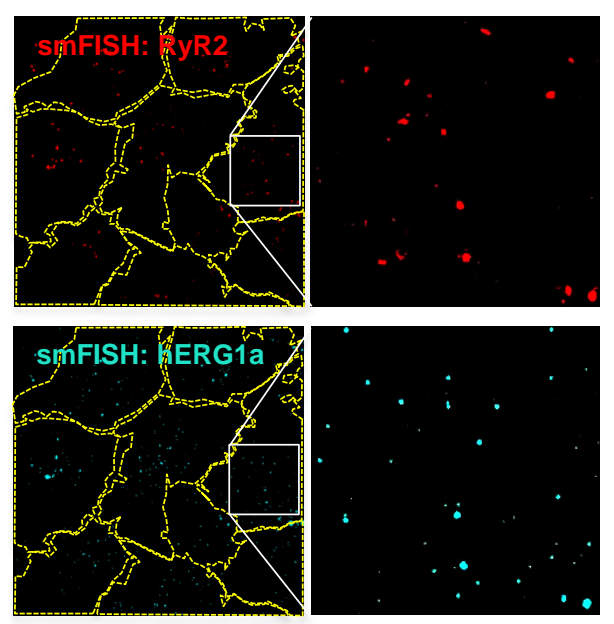

b

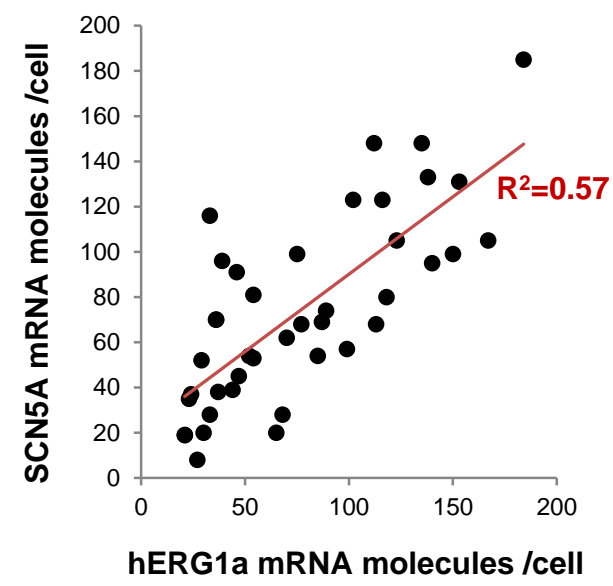

d

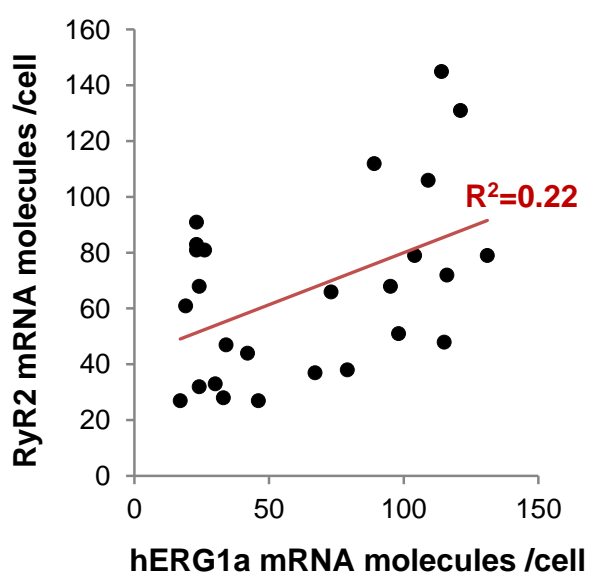

Figure 3: hERG1a and SCN5A transcript expression levels correlate. a, Representative confocal images and enlargements of double smFISH experiments for SCN5A (red) and $h E R G 1 a$ (cyan) mRNAs. $\mathbf{b}$, The number of mRNA molecules detected per cell in double smFISH experiments were plotted for SCN5A and hERG1a and the coefficient of determination $\mathrm{R}^{2}$ was determined from the Pearson's correlation coefficient $R(n=41$ cells; $N=2)$. c, Representative confocal images and enlargements of double smFISH experiments for RyR2 (red) and hERG1a (cyan) mRNAs. d, The number of $h E R G 1$ a mRNA was plotted against the number of $R Y R 2$ mRNAs per cells and showed a low correlation in their expression ( $n=26$ cells; $N=2)$. 
a
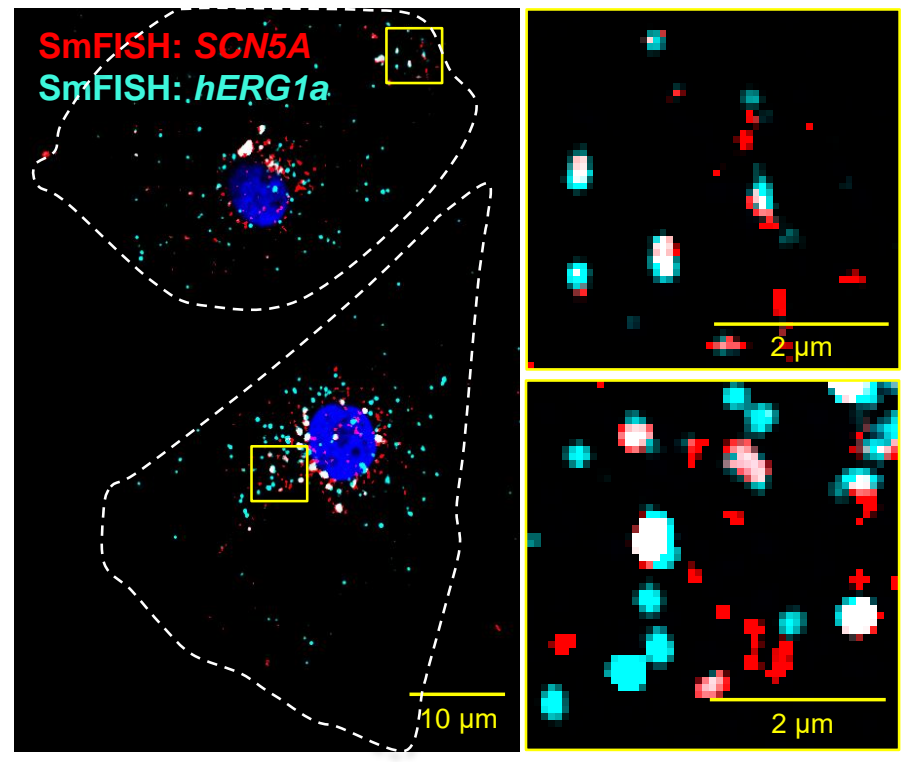

d
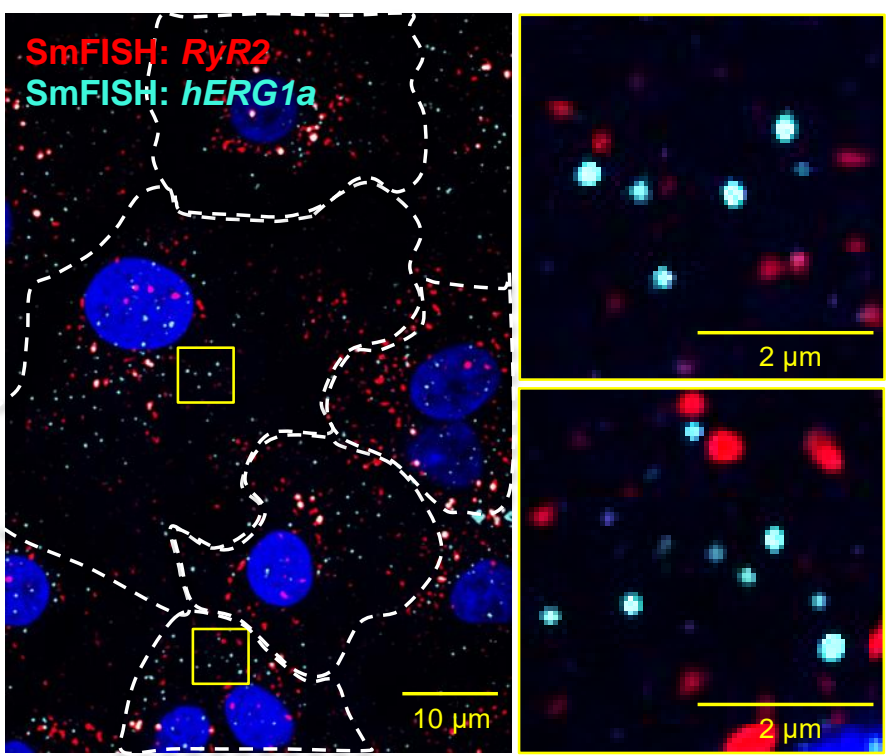

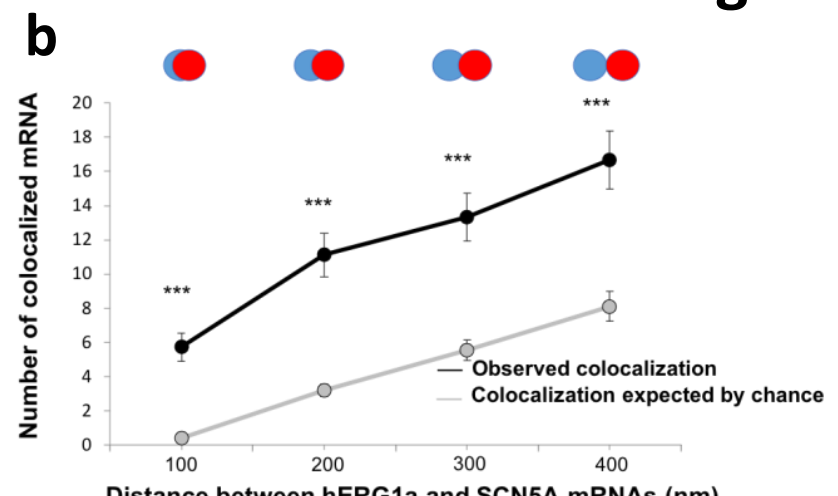

Fig. 4

C

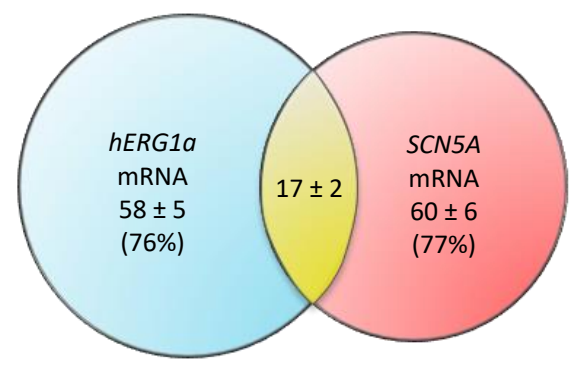

e

- Observed colocalization Colocalization expected by chance

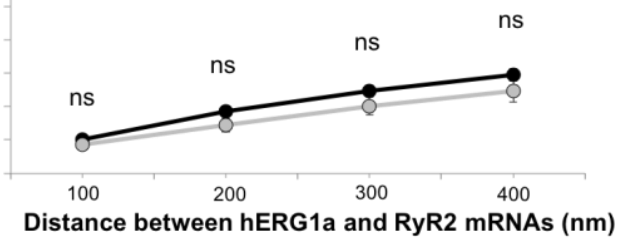

Figure 4: hERG1a and SCN5a transcript colocalization. a, Representative confocal images and enlargement (outlined in yellow) of iPSC-CMs subjected to smFISH showing the colocalization of hERG1a and SCN5A mRNAs. b, Comparison of the average number of associated $h E R G 1 a$ and $S C N 5 A$ mRNAs particles observed vs. expected by chance using different overlap criteria illustrated (mean $\pm S E ; n=41$ cells; $N=2$ ). $c$, Diagram illustrating that the association of $h E R G 1 a$ and SCN5A mRNAs account for $24 \%$ and $23 \%$ of their total population respectively. d, Representative confocal images of smFISH for hERG1a and RyR2 transcripts. e, Comparison of the average number of associated $h E R G 1 a$ and RyR2 mRNAs particles observed vs. expected by chance using different overlap criteria (mean $\pm \mathrm{SE} ; \mathrm{n}=26$ cells; $\mathrm{N}=2$ ). 
a
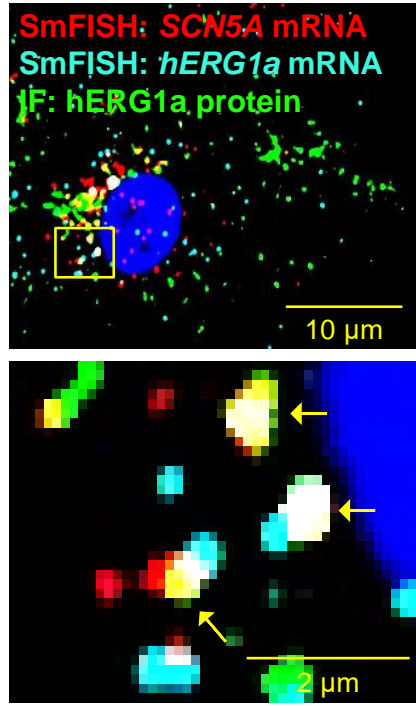

b

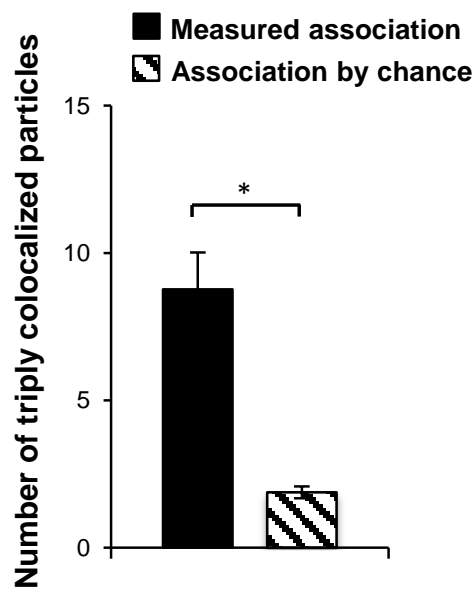

C

口 hERG1a mRNA/protein association 口 Single hERG1a mRNA

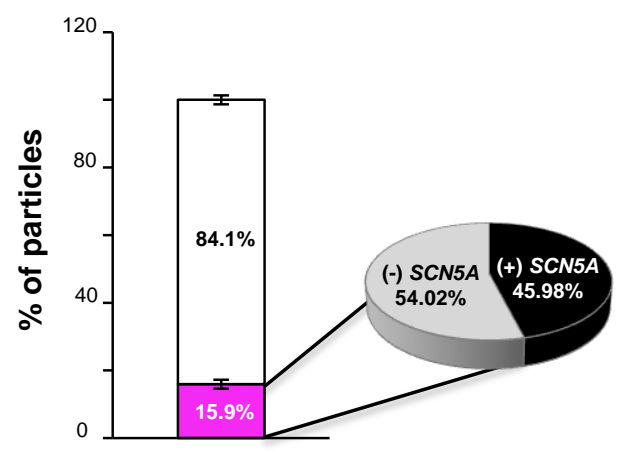

d

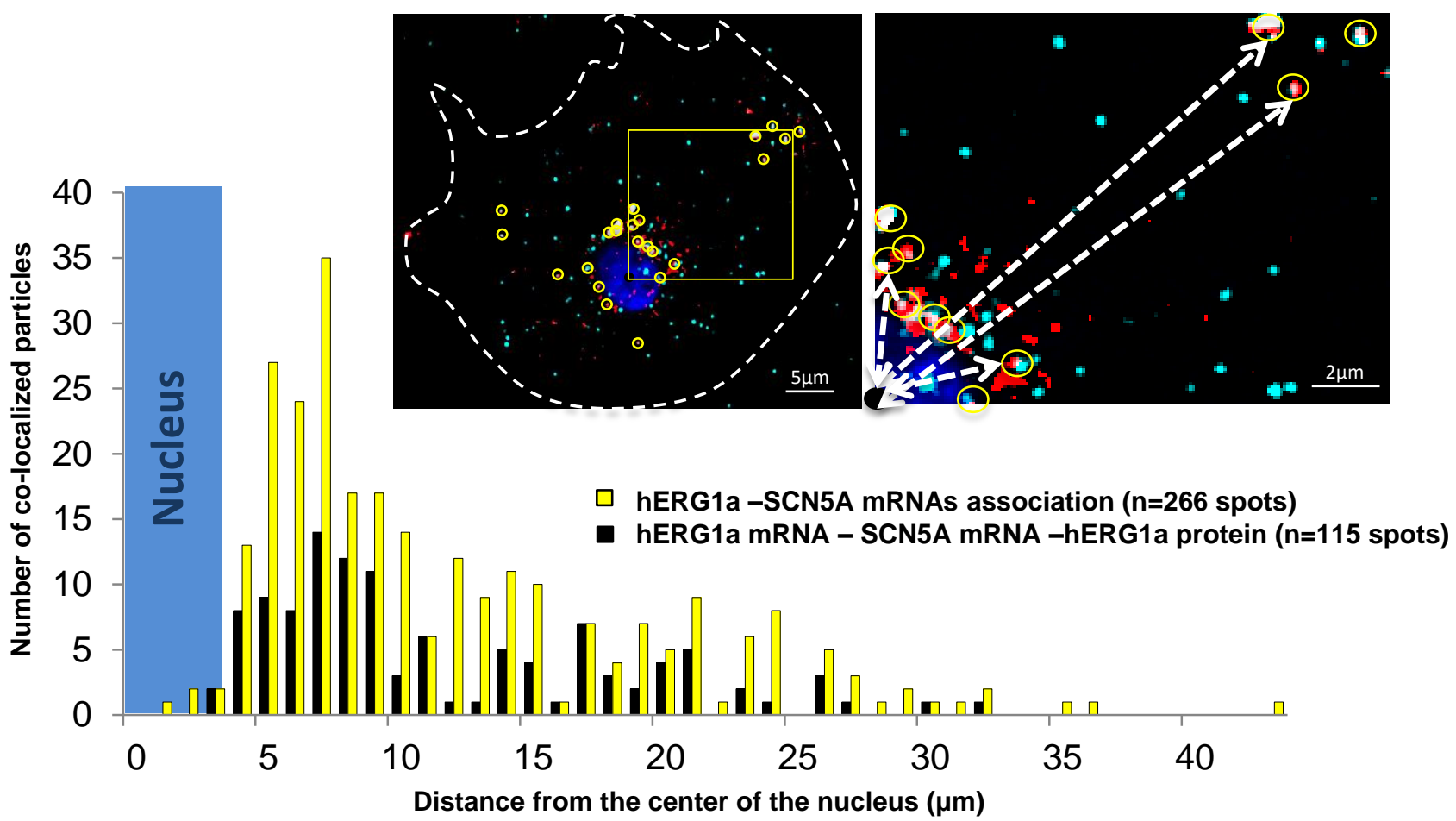

Figure 5: Cotranslational association of hERG1a protein and hERG1a and SCN5A mRNAs. a, Representative confocal images and enlargement of iPSC-CMs subjected to immunofluorescence (IF) combined with smFISH protocol. Arrows indicate triply colocalized particles. $\mathbf{b}$, The average number of particles comprising $h E R G 1 a$ and SCN5A mRNAs and hERG1a protein per cell compared to the expected number based on chance using a maximum distance of 2 pixels between center of mass (minimum $50 \%$ overlap; mean $\pm \mathrm{SE} ; \mathrm{n}=13$ cells, $\mathrm{N}=2$ ). $\mathrm{c}$, Histogram showing that $16 \%$ of $h E R G 1 a$ mRNA associate with $h E R G 1$ a protein (actively translated population); of that percentage, $46 \%$ also interact with SCN5A transcripts. (mean $\pm S E ; n=13$ cells; $N=2$ ) $d$, Histogram showing the distribution of colocalized mRNA spots through the cytoplasm and from the nucleus revealing that RNP complexes are mostly localized within $10 \mu \mathrm{m}$ from the nucleus. In the top right corner, representative examples of colocalized spots (yellow circles) and analysis of distance from the nucleus (white dashed arrows). 


\section{Fig. 6}
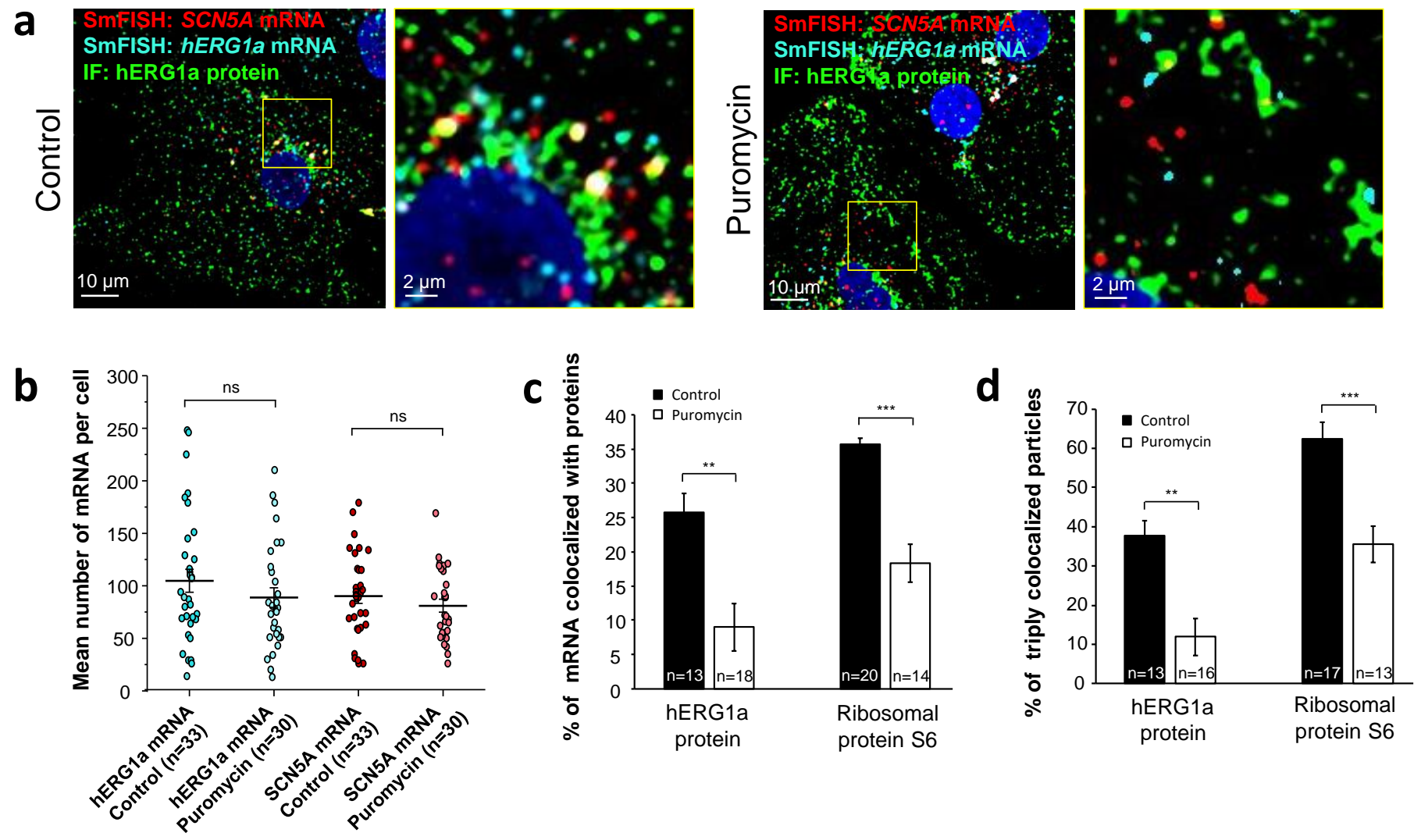

Figure 6: Distribution and association of $h E R G 1 a$ and SCN5A transcripts under puromycin treatment in iPSC-CMs. a, Representative confocal images and enlargement (outlined in yellow) of iPSC-CMs subjected to immunofluorescence combined with smFISH for control cells (left panel) or cells treated with $100 \mu \mathrm{M}$ puromycin for 15 min (right panel). b. The number of mRNAs detected per cell was plotted for SCN5A and hERG1a in the presence of puromycin and compared to control cells (lines represent mean $\pm \mathrm{SE}$ ). c, Histogram showing the reduction of association between $h E R G 1 a$ mRNA and hERG1a protein after puromycin treatment compared to non-treated cells (mean $\pm \mathrm{SE}$ ). $\mathbf{d}$, Histogram showing that the \% of triply colocalized particles (hERG1a protein or the ribosomal subunit S6 associated with both $h E R G 1 a$ and SCN5A mRNAs) is decreased upon puromycin treatment (mean $\pm \mathrm{SE})$. 
a

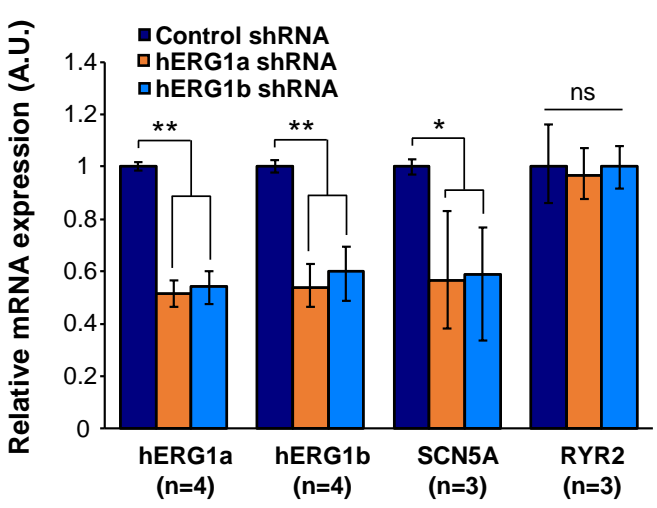

b

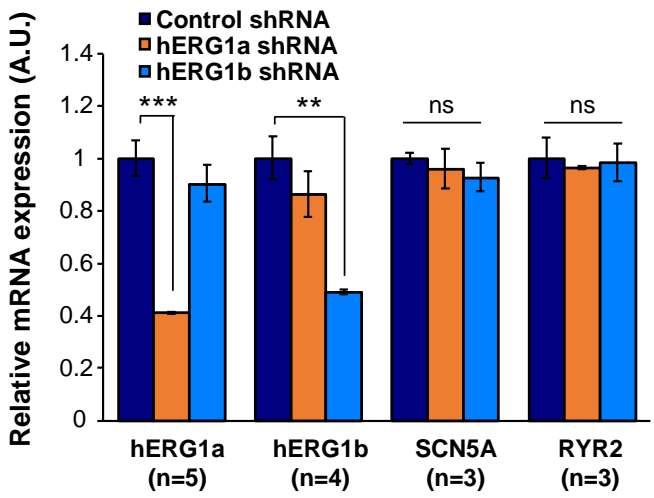

C

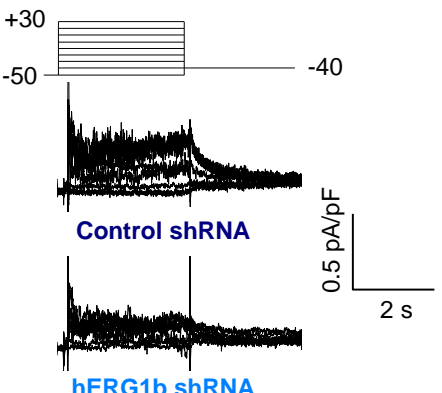

f

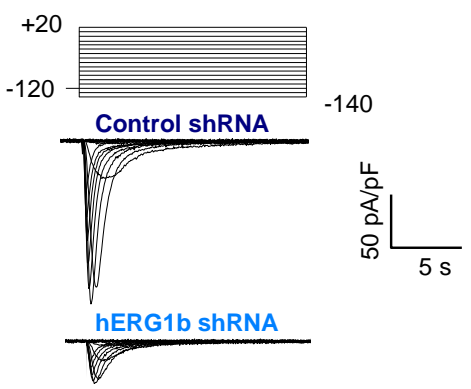

i

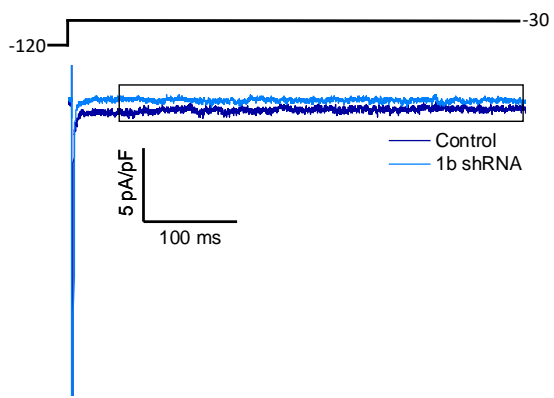

g d
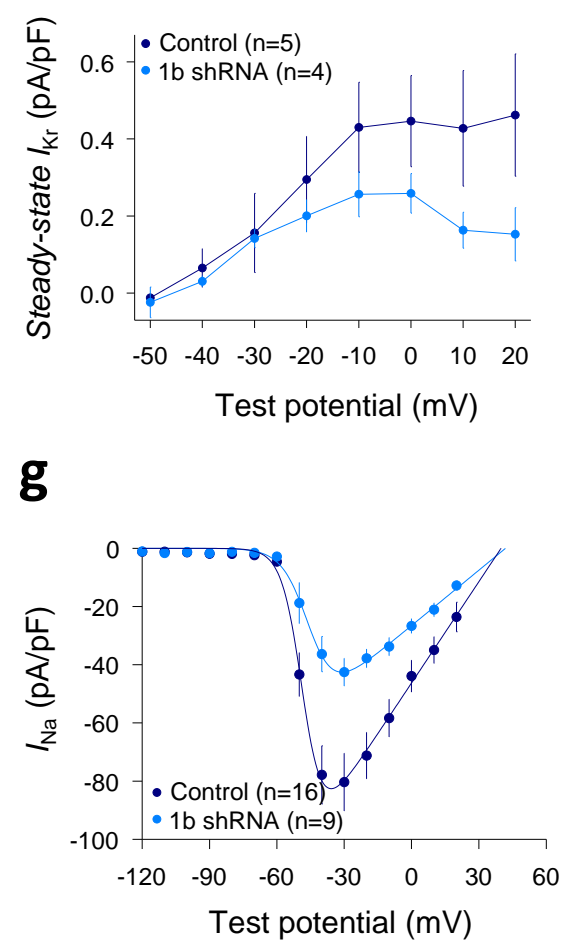

j

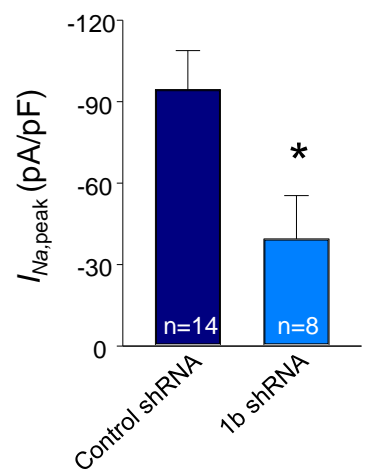

e

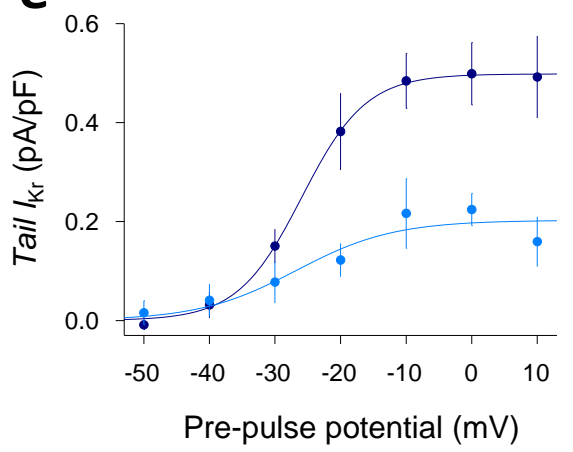

h

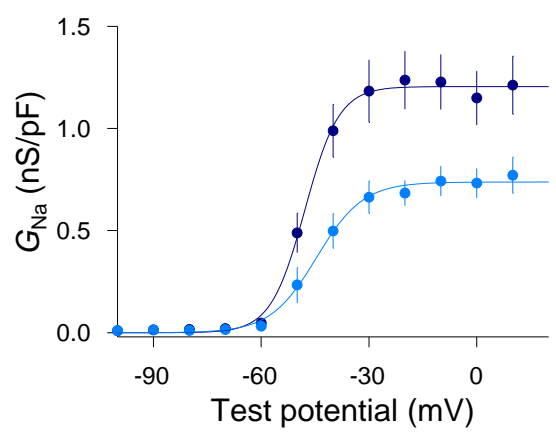

k

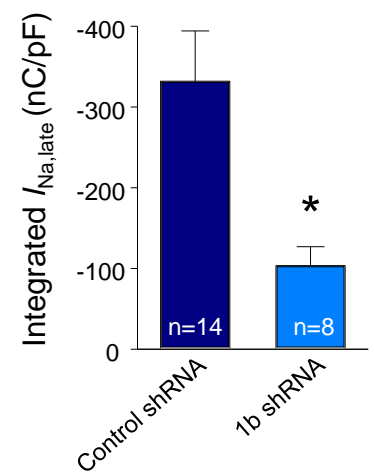


Figure 7: Co-knockdown of $I_{K r}$ and $I_{N a}$ by hERG transcript-specific shRNA. a, Effects of $h E R G 1 a$ or $h E R G 1 b$ silencing on channel mRNA expression levels detected by RT-qPCR (mean $\pm 95 \% \mathrm{Cl}$ ) in IPSC-CMs. A non-targeting shRNA (scrambled shRNA) is used as a control. $\mathbf{b}$, Effects of specific $h E R G 1 a$ or $h E R G 1 b$ silencing on ion channel mRNAs expressed alone in HEK293 cells.

c, Representative family of traces show $I_{\mathrm{Kr}}$ in presence of control (upper) or hERG1b shRNA (lower). d, Summary of steady-state current density vs. test potential shows effect of hERG1b shRNA (mean \pm $\mathrm{SE}$ ). e, Effects of $1 \mathrm{~b}$ shRNA on peak tail current vs. pre-pulse potential (mean $\pm \mathrm{SE}$ ). $\mathbf{f}$, Representative family of traces recorded from iPSC-CMs showing effects of hERG1b-specific shRNA compared to control shRNA on peak $I_{\mathrm{Na}} \mathbf{g}$, Summary current-voltage plot of peak $I_{\mathrm{Na}}$ vs. test potential (mean \pm SE). $\mathbf{h}$, Summary conductance $(G)$-voltage plot based on data from $g$ (mean \pm SE). i, Late sodium current representative trace in control and $1 \mathrm{~b}$ shRNA-transfected cells, measured by applying a single pulse protocol of $800 \mathrm{~ms}$. j, Summary statistics of peak $I_{\mathrm{Na}}$ showed a decrease upon transfection with hERG1b shRNA (mean $\pm \mathrm{SE}$ ). $\mathbf{k}$, Late $I_{\mathrm{Na}}$ measured as the integral from 50 to 800 $\mathrm{ms}$ from the beginning of the pulse showed a decrease upon transfection with hERG1b shRNA (mean $\pm \mathrm{SE})$. 

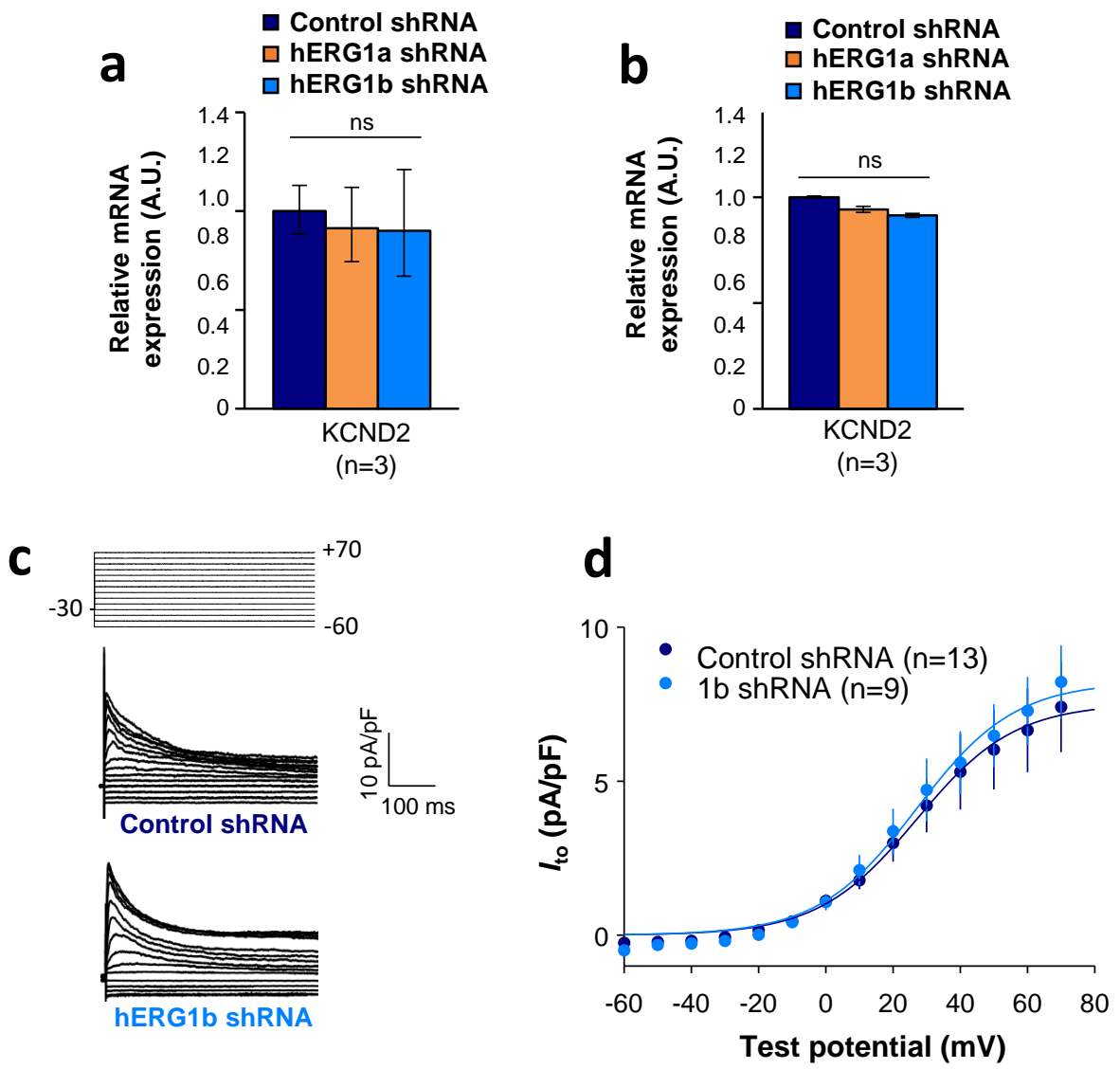

Figure 8: Effects of hERG1b silencing on $I_{t o}$ and $K_{\mathrm{v}} 4.2$ channels in iPSC-CMs. a, Effects of $h E R G 1 a$ or $h E R G 1 b$ silencing on $\mathrm{K}_{\mathrm{v}} 4.2$ channel mRNA expression levels detected by RT-qPCR (mean $\pm 95 \% \mathrm{Cl}$ ) in IPSC-CMs. A non-targeting shRNA (scrambled shRNA) is used as a control. $\mathbf{b}$, Effects of specific $h E R G 1 a$ or $h E R G 1 b$ silencing on $\mathrm{K}_{\mathrm{v}} 4.2$ channel mRNAs expressed alone in HEK293 cells. c, Representative family of traces show $I_{\text {to }}$ in presence of control (upper) or hERG1b shRNA (lower). d, Summary of steady-state current density vs. test potential shows effect of hERG1b shRNA (mean \pm SE). 
Supplementary 


\begin{tabular}{|c|c|c|}
\hline hERG1a probes & SCN5A probes & RyR2 probes \\
\hline caagactggactgcgggc & cccgaggtaataggaagttt & tccatttttccacatcaact \\
\hline agcactaggcttcgggtg & tagagatctggcagcttttt & acatccaatttttccttgga \\
\hline caggaaggtgttctgcgg & agtcttttgggtgctataga & tgtatagatcccattctcac \\
\hline acttgcggatgatggtgt & gaagatggtcttgcctttat & catgctgggatctcgacaaa \\
\hline aacttacggctctggccc & ggactgaggacatacaaggc & caaggccccttataaatcta \\
\hline ccgagcgttggcgatgat & gtgtactcgacatacttggt & gaagtagccaatgagatcct \\
\hline agatgacggcgcagttct & gaccagagactcaaaggtgt & tctgttctgtttgtcttcat \\
\hline cagaagccgtcgttgcag & ccgaaggaaagtgaacgcgt & agtcgagggagccagaaaat \\
\hline cgagtagccgcacagctc & aatcacactaaagtccagcc & acatccagaaccttgtgatt \\
\hline gcagggtcgctgcatcac & attcagttgtgtatgccatg & tggcaaacacagagtgagca \\
\hline cgtgcaggaagtcgcagg & tgcgtaaggctgagacattg & tcacagatgagatgctggtt \\
\hline cagtgcctgcgcgatctg & ccaggcaaaggaatcgaagc & atggttcacaagacgtgtct \\
\hline gatttccactttgcgctc & caggcggaagagtgcaagaa & gatgaaggccatcaaatcca \\
\hline cccatctttccggtagaa & tcagtaaacgggtccatgac & ttggtgagcttacagtacga \\
\hline ccaccagacataggaagc & tgtgttgagtacgatgcaca & aggttgtccattaattcgga \\
\hline ctcgttcttcacgggcac & tcctcgaattcacttgtcat & agttctttcttgcttgtact \\
\hline aacatgatgacagcccca & gggcaatgatcttgaaggtc & acttgtcagctggtaattct \\
\hline ccacctcgaaattgagga & tggaagtagtagtaggggtc & tatgtgcattttctgccaac \\
\hline accatgtccttctccatc & gatgacgatgatgctgtcga & ggaacaaggcgaggatttct \\
\hline gtggttggtgtcatgagc & ccgatgatcttgatgagtgt & cacggaagattcggaacctt \\
\hline cttcaggcggaaggtctt & gaacacgatgatggctagca & gtgtgaacatcatggtgtgt \\
\hline ctgtcacttcgtccaggg & agtagttcttgccaaagagc & ctgacatcctttccaaagtt \\
\hline tgccacgtggttgtccat & aggttgccaatgaccataac & atggtaatatccctgtttgt \\
\hline gtcggggttgaggctgtg & atgaatgtctcgaaccagct & cagtgttgctgttctgagaa \\
\hline ctttctcgggagcgcgtc & cactgctgagtaggatcatg & tttcctgggcataatctttg \\
\hline catggcctcgatgtcgtc & ctaggtagatgtcctcgaag & ggctttgttcttctaagcaa \\
\hline tgcgcagtgggtgcatgg & caagcagaaccttgatggtc & tacgtggacgtttgcatcaa \\
\hline gtggagttgagcaagccg & atctccagcacgaagacata & agtcaaagcctgtgtcatac \\
\hline cacgaggtcggagtccga & agtacttcttgaagccgtag & tggcaatgaatgtgagcagc \\
\hline tgctaatggtgcggtagc & aatcgtgacagagctctcag & ggacttgtagcttgtgcaaa \\
\hline ttgagggtgatttgggga & cgaggaggacgttcatgatg & gagagaggcatcacattctt \\
\hline gcccttgaggtccacaaa & tgttcacgatggtgtagttc & ttcttgtgctcactcttgaa \\
\hline gcgaagccaagaaggggt & agttcaaggactcacactgg & ttcgagacacatctaccttc \\
\hline gatctcacggtcactggt & ccacgttgtcaaagttgact & gggacaatgtactcgttgtt \\
\hline \multirow[t]{14}{*}{ ctcctttatcttaggtgc } & gctgcatacataatgtccat & gcttacaaaactgggggagg \\
\hline & tcctctgtcatgaagatgtc & acacactgggctcaatcaac \\
\hline & catggcattgtagtacttct & ttgatctgttcttgaggtgg \\
\hline & aatatgaagccctggtactt & agacgccctctaattgttaa \\
\hline & catcatggtcaccatattca & agtcactctcaactggtttt \\
\hline & cagcttgacaatacactcgc & gggtcttcaatgacagactc \\
\hline & ttggtgaagtagtagtggcg & ctccgaatgagcaatctcac \\
\hline & tggagaggatgacaaccacg & atggacctaattctgatggc \\
\hline & aagagcgtcggggagaagaa & tgaacctcaatcccatagac \\
\hline & catcatgagggcaaagagca & ctgtgcaaaggtaccgattg \\
\hline & acatgacgaggaagagcagc & agagaggagcacatcttgtt \\
\hline & ccatgccaaagatggagtag & gaacagcccttagaaagtct \\
\hline & cccacttgacataagcgaag & aaacttctatggaatcccgc \\
\hline & taggagatcttggatgggtt & ttctgagtaagtgctgcatc \\
\hline
\end{tabular}

Table S1: List of probes used in smFISH experiments. The probes were designed using Stellaris $\mathbb{R}$ probe Designer software with the following parameters: 18 to 20 nucleotides oligo length, a masking level of 5 , a minimum spacing length of 2 nucleotides and a maximum number of probes of 48 . Due to the length of the N-terminal specific sequence for $h E R G 1$ a mRNA, the number of probes used to detect hERG1a is limited to 35 . 


\begin{tabular}{|c|c|c|c|c|c|c|}
\hline & & $\begin{array}{l}400 \mathrm{~nm} \\
\text { Touching }\end{array}$ & $\begin{array}{c}300 \mathrm{~nm} \\
20 \% \text { overlap }\end{array}$ & $\begin{array}{c}200 \mathrm{~nm} \\
45 \% \text { overlap }\end{array}$ & $\begin{array}{c}100 \mathrm{~nm} \\
67 \% \text { overlap }\end{array}$ & \\
\hline $\begin{array}{l}\text { hERG1a/SCN5A } \\
\text { ( } n=41 \text { cells) }\end{array}$ & $\begin{array}{l}\text { Expected by chance } \\
\text { Measured } \\
P \text { value }\end{array}$ & $\begin{array}{c}8.10 \pm 0.87 \\
16.68 \pm 1,70 \\
1.57 \mathrm{E}-9(* * *)\end{array}$ & $\begin{array}{c}5.56 \pm 0.61 \\
13.34 \pm 1.38 \\
4.71 \mathrm{E}-9\left(^{* * *}\right)\end{array}$ & $\begin{array}{c}3.20 \pm 0,34 \\
11.12 \pm 1.28 \\
3.49 \mathrm{E}-10(* * *)\end{array}$ & $\begin{array}{c}0.40 \pm 0.04 \\
5.73 \pm 0.82 \\
4.51 \mathrm{E}-8(* * *)\end{array}$ & 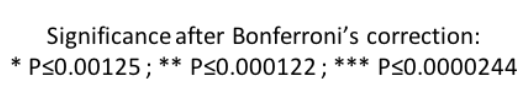 \\
\hline $\begin{array}{l}\text { hERG1a/RyR2 } \\
\text { ( } n=26 \text { cells) }\end{array}$ & $\begin{array}{l}\text { Expected by chance } \\
\text { Measured } \\
P \text { value }\end{array}$ & $\begin{array}{c}4.92 \pm 0.66 \\
5.92 \pm 0.36 \\
0.16 \text { (ns) }\end{array}$ & $\begin{array}{c}4.03 \pm 0.54 \\
4.96 \pm 0.30 \\
0.16 \text { (ns) }\end{array}$ & $\begin{array}{c}2.88 \pm 0.39 \\
3.69 \pm 0.26 \\
0.14 \text { (ns) }\end{array}$ & $\begin{array}{c}1.74 \pm 0,23 \\
2.04 \pm 0,24 \\
0.38 \text { (ns) }\end{array}$ & $\begin{array}{l}\text { Significance after Bonferroni's correction: } \\
*^{*} \mathrm{P} \leq 0.00197 ;{ }^{* *} \mathrm{P} \leq 0.000193 ;{ }^{* * *} \leq 0.0000385\end{array}$ \\
\hline $\begin{array}{l}\text { hERG1a/GAPDH } \\
\text { ( } n=13 \text { cells) }\end{array}$ & $\begin{array}{l}\text { Expected by chance } \\
\text { Measured } \\
P \text { value }\end{array}$ & $\begin{array}{c}14.87 \pm 2.65 \\
13.54 \pm 1.68 \\
0.53(n s)\end{array}$ & $\begin{array}{c}7.47 \pm 1.33 \\
8.46 \pm 1.15 \\
0.20 \text { (ns) }\end{array}$ & $\begin{array}{c}5,48 \pm 1,23 \\
5,24 \pm 0,72 \\
0.19 \text { (ns) }\end{array}$ & $\begin{array}{c}0.54 \pm 0.10 \\
0.92 \pm 0.15 \\
0.24 \text { (ns) }\end{array}$ & $\begin{array}{l}\text { Significance with Bonferroni correction: } \\
{ }^{*} \mathrm{P} \leq 0.0039 ;{ }^{* *} \mathrm{P} \leq 0.000386 ;{ }^{* * *} \mathrm{P} \leq 0.000077\end{array}$ \\
\hline $\begin{array}{l}\text { SCN5A/GAPDH } \\
\text { ( } n=28 \text { cells) }\end{array}$ & $\begin{array}{l}\text { Expected by chance } \\
\text { Measured } \\
\text { P value }\end{array}$ & $\begin{array}{c}17.31 \pm 1.71 \\
15.92 \pm 1.64 \\
0.16(n s)\end{array}$ & $\begin{array}{c}12.73 \pm 1.25 \\
9.92 \pm 1.04 \\
0.002(\mathrm{~ns})\end{array}$ & $\begin{array}{c}6.82 \pm 0.67 \\
5.32 \pm 0.60 \\
0.0006\left(^{*}\right)\end{array}$ & $\begin{array}{c}0.92 \pm 0.09 \\
1.62 \pm 0.28 \\
0.012(n s)\end{array}$ & $\begin{array}{l}\text { Significance after Bonferroni's correction: } \\
{ }^{*} \mathrm{P} \leq 0.0013 ;{ }^{* *} \mathrm{P} \leq 0.000186 ;{ }^{* * *} \mathrm{P} \leq 0.0000275\end{array}$ \\
\hline
\end{tabular}

Table S2: Summary of colocalization analysis perfomed in iPSC-CMs for different association criteria. Comparison of the average number of mRNAs particles observed to be associated and the expected number based on chance alone using centroid positions and different association criteria (from touching to $67 \%$ overlap). The significance is tested with a paired t-test Bonferroni's correction. The number of $h E R G 1 a$ and SCN5A mRNAs observed to be associated is significantly above that expected by chance alone for all association criteria tested while no significant differences are observed for $h E R G 1$ a/RyR2, hERG1a/GAPDH and SCN5A/GAPDH associations. 


\begin{tabular}{|c|c|c|c|c|c|}
\hline & & $\begin{array}{c}\text { hERG1a/SCN5A } \\
\text { (41 cells) }\end{array}$ & $\begin{array}{c}\text { hERG1a/RyR2 } \\
\text { ( } 26 \text { cells) }\end{array}$ & $\begin{array}{l}\text { hERG1a/GAPDH } \\
\text { (13 cells })\end{array}$ & $\begin{array}{l}\text { SCN5A/GAPDH } \\
\text { (28 cells) }\end{array}$ \\
\hline $\begin{array}{c}\text { Pearson's } \\
\text { test }\end{array}$ & $\begin{array}{l}\text { Correlation coefficient } \mathbf{R} \\
\text { Coefficient of determination } \mathbf{R}^{2} \\
\mathbf{P} \text { value } \\
\text { Slope of linear regression line } \\
\text { Significance after Bonferroni } \\
\text { correction }\end{array}$ & $\begin{array}{c}0.7546 \\
0.56943 \\
0.00001\left(^{* * *}\right) \\
0.6844 \\
{ }^{*} \mathrm{P}<0.038 \\
{ }^{* *} \mathrm{P}<0.0076 \\
{ }^{* * *} \mathrm{P}<0.00076\end{array}$ & $\begin{array}{c}0.4654 \\
0.2166 \\
0.01658\left(^{*}\right) \\
0.3732 \\
{ }^{*} P<0.024 \\
{ }^{* *} P<0.0049 \\
{ }^{* *} P<0.00049\end{array}$ & $\begin{array}{c}0.4197 \\
0.1761 \\
0.153373(n s) \\
0.2662 \\
{ }^{*} P<0.023 \\
{ }^{* *} P<0.0046 \\
\text { *** } P<0.00046\end{array}$ & $\begin{array}{c}0.4808 \\
0.2315 \\
0.0096\left(^{*}\right) \\
1.4651 \\
{ }^{*} P<0.025 \\
{ }^{* *} P<0.005 \\
\text { *** } P<0.0005\end{array}$ \\
\hline $\begin{array}{c}\text { Spearman's } \\
\text { test }\end{array}$ & $\begin{array}{l}\text { Correlation coefficient } \rho \\
\text { P value } \\
\text { Significance after Bonferroni } \\
\text { correction }\end{array}$ & 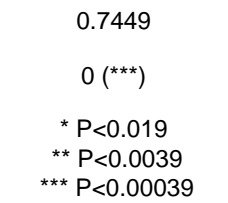 & $\begin{array}{c}0.3224 \\
0.1084(n s) \\
{ }^{*} \mathrm{P}<0.0055 \\
{ }^{* *} \mathrm{P}<0.0011 \\
\text { *** } \mathrm{P}<0.00011\end{array}$ & $\begin{array}{c}0.4890 \\
0.08991\left(^{*}\right) \\
{ }^{*} P<0.013 \\
{ }^{* *} P<0.0027 \\
\text { *** } P<0.00027\end{array}$ & $\begin{array}{c}0.3692 \\
0.05315 \text { (ns) } \\
{ }^{*} P<0.0061 \\
{ }^{* *} P<0.0012 \\
{ }^{* *} P<0.00012\end{array}$ \\
\hline
\end{tabular}

Table S3: Summary of correlation analysis perfomed in iPSC-CMs. The linear correlation between the different combination of mRNAs was evaluated using the Pearson correlation coefficient. Because the Pearson coefficient is highly sensitive to outliers and only assess linear correlation, the Spearman's correlation coefficient was also calculated. Both tests revealed a significant correlation between hERG1a and SCN5A mRNAs and no significant correlation for hERG1a/RyR2, hERG1a/GAPDH and SCN5A/GAPDH pairs. Levels of significance were adjust with a Bonferroni correction taking into account correlation coefficients and either linear correlation or non-linear correlation for Pearson's and Spearman's test respectively. 


\begin{tabular}{|c|c|c|c|c|c|}
\hline Condition & $\mathbf{G}_{\max }(\mathbf{n S} / \mathbf{p F})$ or $\mathbf{I}_{\max }(\mathbf{p A} / \mathbf{p F})$ & $\mathbf{V}_{\mathbf{1 / 2}}(\mathbf{m V})$ & $\mathbf{k}(\mathbf{m V})$ & $\mathbf{V}_{\text {rev }}(\mathbf{m V})$ & $\mathbf{n}$ \\
\hline Activation & & & & & \\
\hline Control & $1.22 \pm 0.1$ & $-45.9 \pm 1.1$ & $-4.7 \pm 0.4$ & $36.5 \pm 3.0$ & 16 \\
\hline 1b shRNA & $0.73 \pm 0.1$ & $-45.7 \pm 1.6$ & $-4.8 \pm 0.5$ & $31.7 \pm 3.2$ & 9 \\
\hline Inactivation & & & & & \\
\hline Control & $-54.1 \pm 7.7$ & $-89.8 \pm 1.3$ & $7.2 \pm 0.3$ & & 16 \\
\hline 1b shRNA & $-33.2 \pm 9.7$ & $-88.6 \pm 1.9$ & $6.8 \pm 0.5$ & & 9 \\
\hline
\end{tabular}

Table S4: Voltage dependence of activation and inactivation parameters for the sodium channels in cells transfected with a control shRNA or a hERG1b specific shRNA. Parameters were obtained after fitting to a Boltzmann equation activation and inactivation data.

\begin{tabular}{|c|c|c|c|c|}
\hline Condition & $\mathbf{I}_{\text {max peak-tail }}(\mathbf{p A} / \mathbf{p F})$ & $\mathbf{V}_{\mathbf{1 / 2}}(\mathbf{m V})$ & $\mathbf{k}(\mathbf{m V})$ & $\mathbf{n}$ \\
\hline Control & $0.50 \pm 0.01$ & $-26.0 \pm 0.5$ & $5.6 \pm 0.5$ & 5 \\
\hline 1b shRNA & $0.21 \pm 0.03$ & $-23.1 \pm 4.5$ & $7.1 \pm 5.3$ & 4 \\
\hline
\end{tabular}

Table S5: Voltage dependence of activation of hERG channels in cells transfected with a control shRNA or a hERG1b specific shRNA. Parameters were obtained by fitting the experimental data of the I-V curve of the peak tail $l_{\mathrm{Kr}}$ to a Boltzmann equation. 


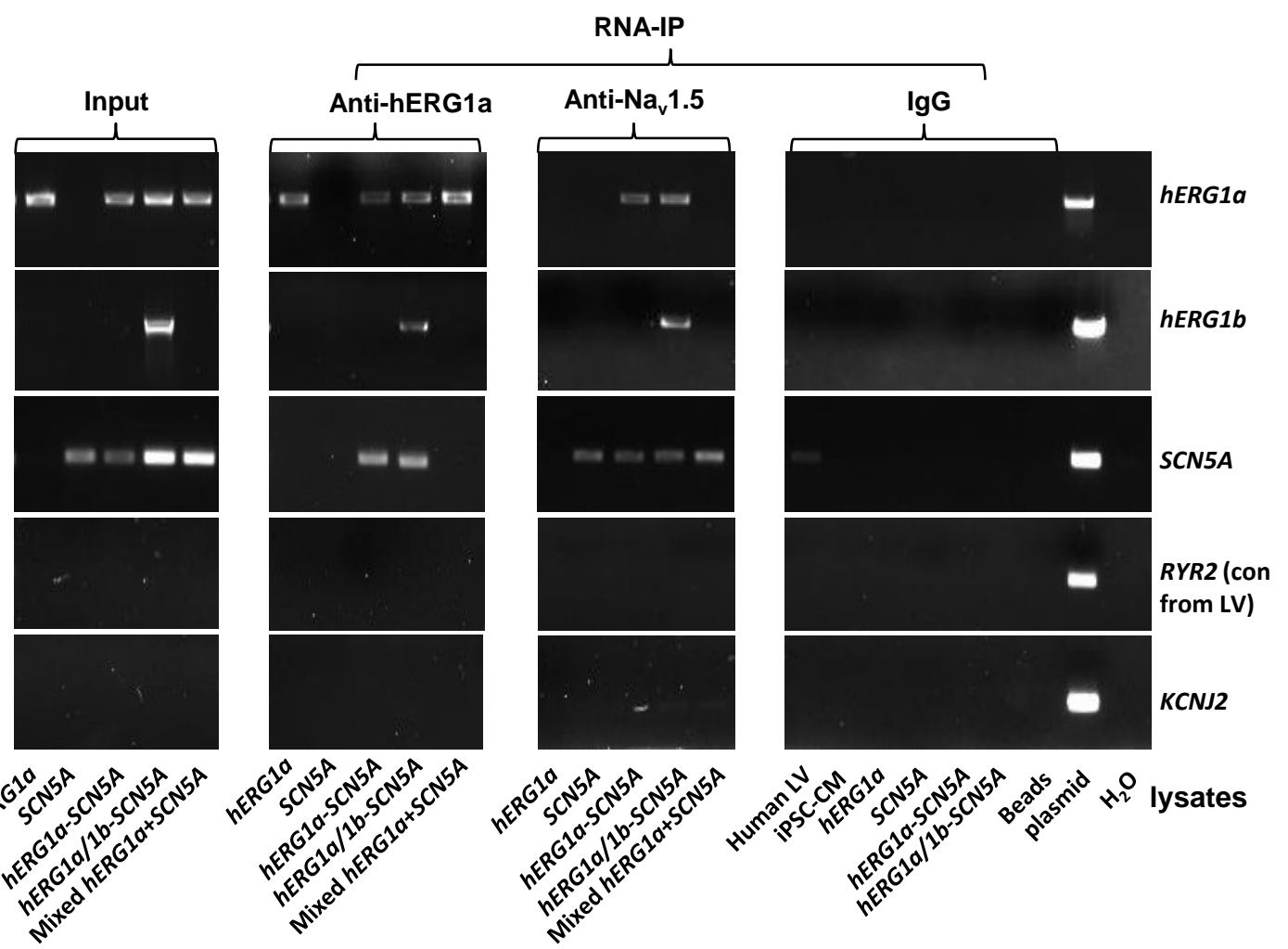

Figure S1: Complete RNA-IP from Figure 1. Lanes 1-6, RT-PCR products from input lysate of human left ventricle (LV), iPSC-CM, and HEK293 cells expressing: $h E R G 1 a ; S C N 5 A ; h E R G 1 a$ plus SCN5A; and $h E R G 1 a$ plus $h E R G 1 b$ and SCN5a. Lane 7 shows RT-PCR product from lysates independently expressing hERG1a and SCN5A, mixed. Lanes 8-14 shows the corresponding RNA-IP's using an anti- hERG1a antibody, followed by a bead-only control and $\mathrm{H} 2 \mathrm{O}$ control. The next group shows the corresponding RNAIP's using the anti-Nav1.5 antibody, followed by a group of IgG controls. $\mathrm{H} 2 \mathrm{O}$ and beads lanes show absence of template contamination; control $(+)$ represents signal amplified from purified plasmid template. 

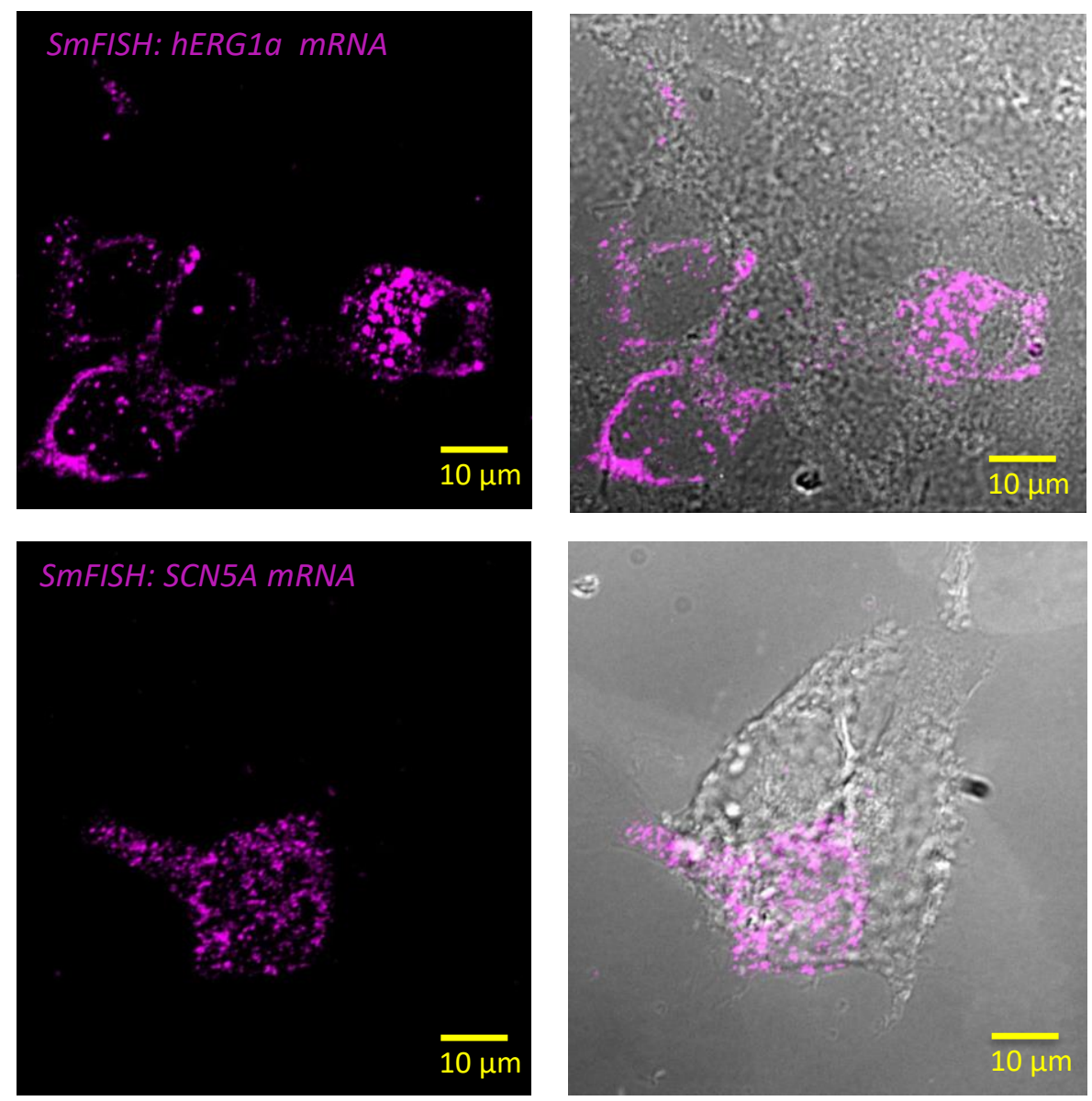

Figure S2: Specificity of the probes used in smFISH experiments. Representative images of smFISH for either hERG1a (top panel) or SCN5A (bottom panel) mRNAs performed in HEK293 cells transiently transfected with $h E R G 1 a$ or SCN5A. Only the cells expressing hERG1a or SCN5A showed a positive signal for smFISH revealing the specificity of the probes used in smFISH experiments. 


\section{a hERG1a mRNA}

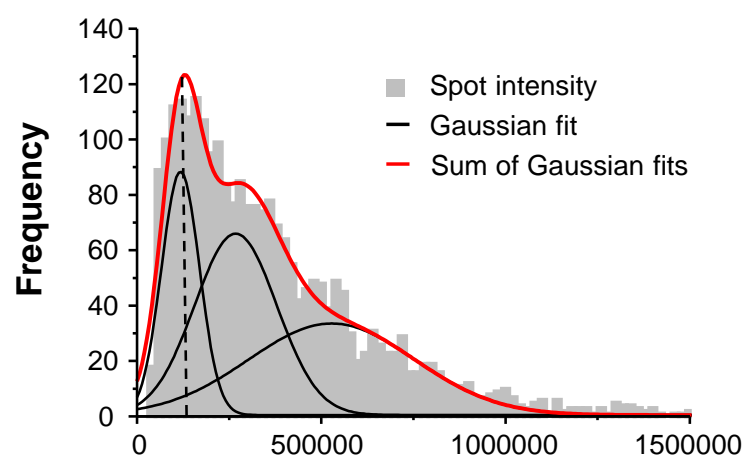

\begin{tabular}{|l|c|c|c|}
\hline Model & \multicolumn{3}{|c|}{ Gauss } \\
\hline Equation & \multicolumn{2}{|c|}{$\mathrm{y}=\mathrm{y} 0+\left(\mathrm{A} /\left(\mathrm{w}^{*} \text { sqrt }(\mathrm{pi} / 2)\right)\right)^{\star} \exp \left(-2^{\star}((\mathrm{x}-\mathrm{xc}) / \mathrm{w})^{\wedge} 2\right)$} \\
\hline Plot & Peak1 & Peak2 & Peak3 \\
\hline $\mathrm{y} 0$ & $0.49 \pm 0.21$ & $0.49 \pm 0.21$ & $0.49 \pm 0.21$ \\
\hline $\mathrm{xc}$ & $117984.83 \pm 2256.31$ & $267703.93 \pm 14735.19$ & $527984.86 \pm 76758.94$ \\
\hline w & $103169.32 \pm 7458.84$ & $222635.33 \pm 40129.29$ & $450302.22 \pm 78120.74$ \\
\hline A & $1.14 \mathrm{E} 7 \pm 2.16 \mathrm{E} 6$ & $1.83 \mathrm{E} 7 \pm 6.81 \mathrm{E} 6$ & $1.87 \mathrm{E} \pm 5.78 \mathrm{E} 6$ \\
\hline
\end{tabular}

Fluorescence intensity (A.U.)

\section{b SCN5A mRNA}

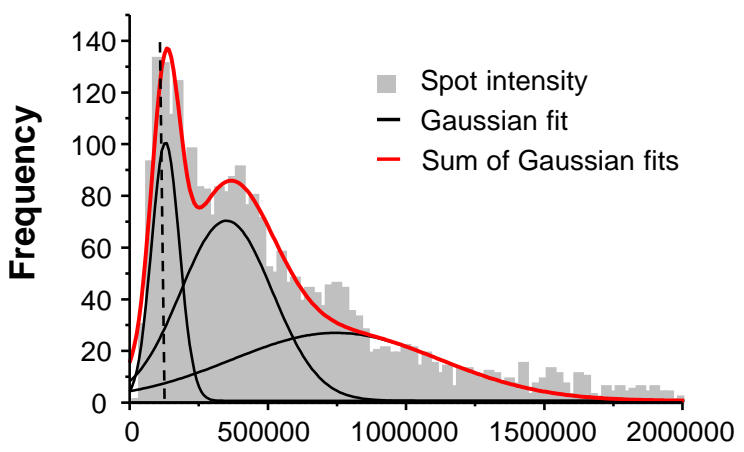

\begin{tabular}{|l|c|c|c|}
\hline Model & \multicolumn{3}{|c|}{ Gauss } \\
\hline Equation & \multicolumn{3}{|c|}{$\mathrm{y}=\mathrm{y} 0+\left(\mathrm{A} /\left(\mathrm{w}^{*} \mathrm{sqrt}(\mathrm{pi} / 2)\right)\right)^{*} \exp \left(-2^{*}((\mathrm{x}-\mathrm{xc}) / \mathrm{w})^{\wedge} 2\right)$} \\
\hline Plot & Peak1 & Peak2 & Peak3 \\
\hline $\mathrm{y} 0$ & $0.71 \pm 0.25$ & $0.71 \pm 0.25$ & $0.71 \pm 0.25$ \\
\hline $\mathrm{xc}$ & $129681.69 \pm 1775.62$ & $350694.45 \pm 10021.78$ & $746868.44 \pm 133741.99$ \\
\hline $\mathrm{w}$ & $100467.91 \pm 5381.31$ & $332189.87 \pm 38494$ & $754612.46 \pm 142927.70$ \\
\hline $\mathrm{A}$ & $1.26 \mathrm{E} 7 \pm 1.15 \mathrm{E} 6$ & $2.90 \mathrm{E} 7 \pm 7.35 \mathrm{E} 6$ & $2.48 \mathrm{E} 7 \pm 7.91 \mathrm{E} 6$ \\
\hline
\end{tabular}

Fluorescence intensity (A.U.)

\section{GAPDH mRNA}

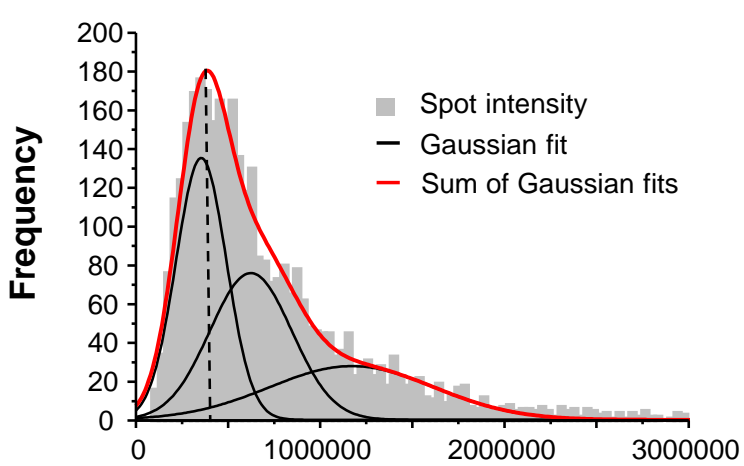

\begin{tabular}{|l|c|c|c|}
\hline Model & \multicolumn{3}{|c|}{ Gauss } \\
\hline Equation & \multicolumn{3}{|c|}{$\mathrm{y}=\mathrm{y} 0+\left(\mathrm{A} /\left(\mathrm{w}^{\star} \mathrm{sqrt}(\mathrm{p} / / 2)\right)\right)^{*} \exp \left(-2^{*}((\mathrm{x}-\mathrm{xc}) / \mathrm{w})^{\wedge} 2\right)$} \\
\hline Plot & Peak1 & Peak2 & Peak3 \\
\hline y0 & $0.35 \pm 0.31$ & $0.35 \pm 0.31$ & $0.35 \pm 0.31$ \\
\hline xc & $354447.18 \pm 11207.17$ & $623535.81 \pm 117199.66$ & $1.17 \mathrm{E} 6 \pm 238744.98$ \\
\hline w & $274182.43 \pm 29650.81$ & $444264.04 \pm 165298.03$ & $893413.86 \pm 242256.38$ \\
\hline A & $4.64 \mathrm{E} 7 \pm 2.18 \mathrm{E} 7$ & $4.21 \mathrm{E} 7 \pm 3.35 \mathrm{E} 7$ & $3.10 \mathrm{E} 7 \pm 1.51 \mathrm{E} 7$ \\
\hline
\end{tabular}

Fluorescence intensity (A.U.)

Figure S3: Single mRNA intensity determination. The distribution of total fluorescence intensity of smFISH signals for hERG1a (2611 spots; a), SCN5A (2815 spots; b), and GAPDH (3507 spots; c). By fitting the histogram to the sum of Gaussian functions (red line), the typical intensity corresponding to a single mRNA molecule (vertical dashed line) was extracted. 
a

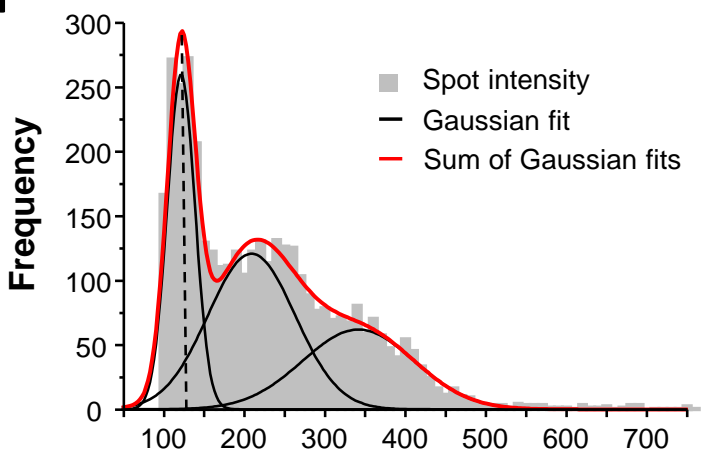

\begin{tabular}{|l|c|c|c|}
\hline Model & \multicolumn{3}{|c|}{ Gauss } \\
\hline Equation & \multicolumn{3}{|c|}{$\mathrm{y}=\mathrm{y} 0+\left(\mathrm{A} /\left(\mathrm{w}^{*} \text { sqrt }(\mathrm{pi} / 2)\right)\right)^{*} \exp \left(-2^{*}((\mathrm{x}-\mathrm{xc}) / \mathrm{w})^{\wedge} 2\right)$} \\
\hline Plot & Peak1 & Peak2 & Peak3 \\
\hline $\mathrm{y} 0$ & $0.23 \pm 0.47$ & $0.23 \pm 0.47$ & $0.23 \pm 0.47$ \\
\hline $\mathrm{xc}$ & $121.20 \pm 0.40$ & $208.75 \pm 5.97$ & $341.49 \pm 19.41$ \\
\hline $\mathrm{w}$ & $34.45 \pm 1.17$ & $108.09 \pm 12.08$ & $138.84 \pm 22.50$ \\
\hline A & $11223.55 \pm 613.86$ & $16353.42 \pm 3157.01$ & $10771.91 \pm 2792.21$ \\
\hline
\end{tabular}

Fluorescence intensity (A.U.)

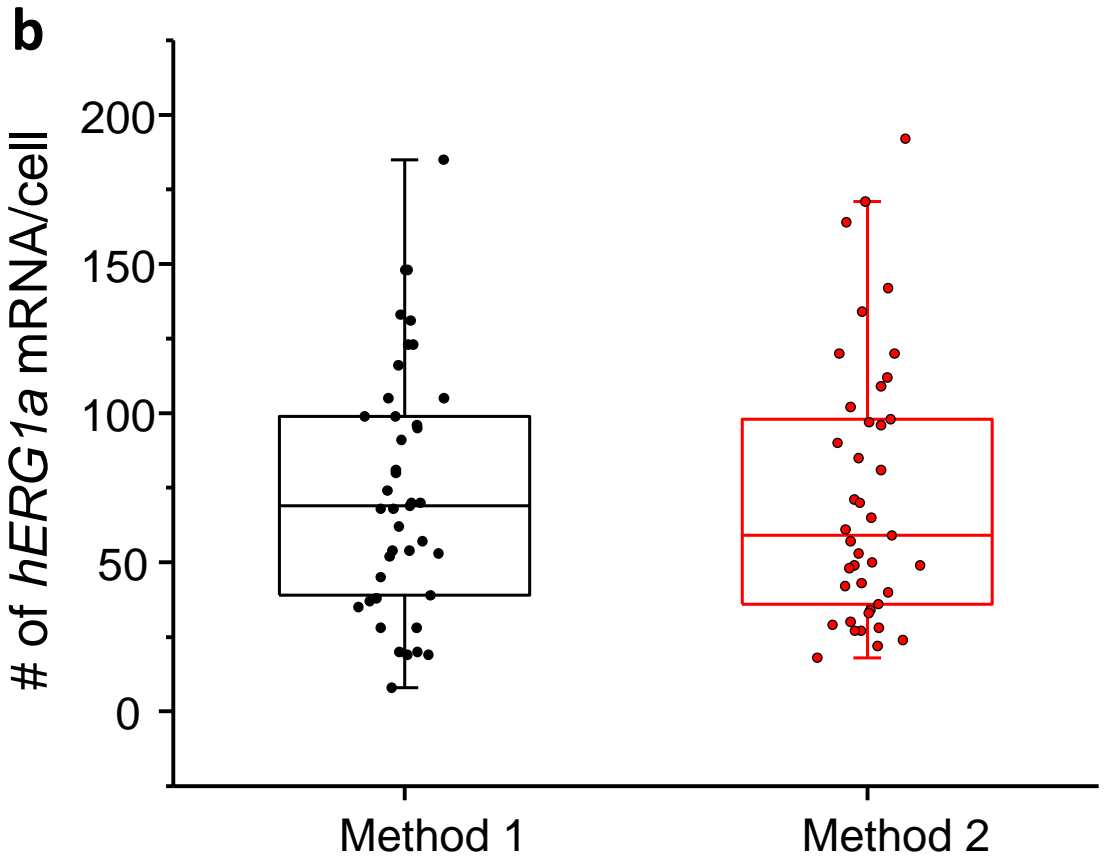

Figure S4: Quantification of mRNA expression using two different methods. a, The distribution of total fluorescence intensity of smFISH signals for hERG1a (2892 spots) obtained using FISHQUANT software for analysis. By fitting the histogram to the sum of Gaussian functions (red line), the typical intensity corresponding to a single mRNA molecule (vertical dashed line) was extracted. $\mathbf{b}$, Comparison of the number of mRNA molecules detected per cells for hERG1a using 2 different methods of analysis (Method 1: manual using ImageJ; Method 2: Semi-automatic using FISHQUANT). 
a

Correlation of SCN5A and GAPDH mRNAs expression

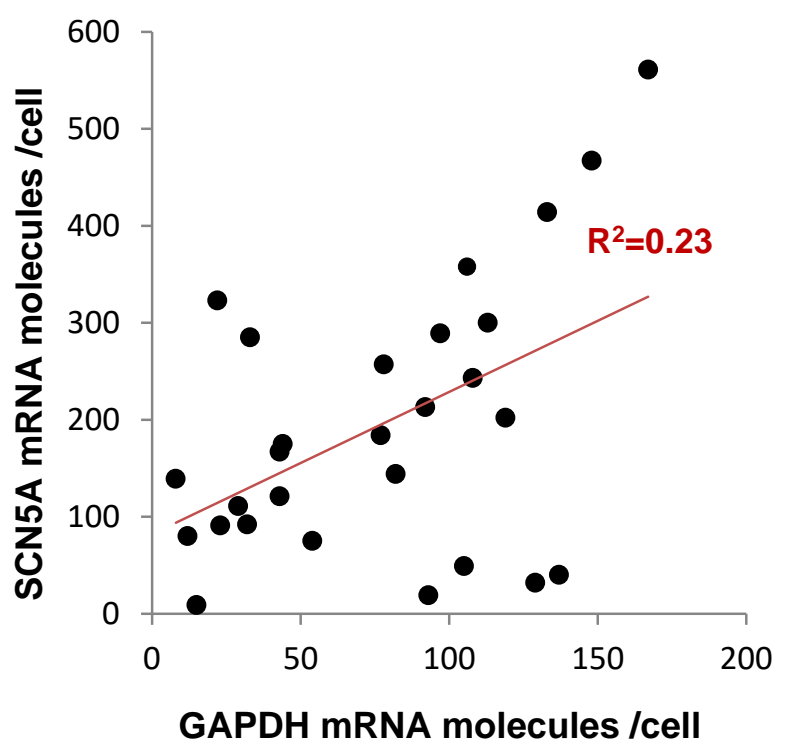

b Correlation of hERG1a and GAPDH mRNAs expression

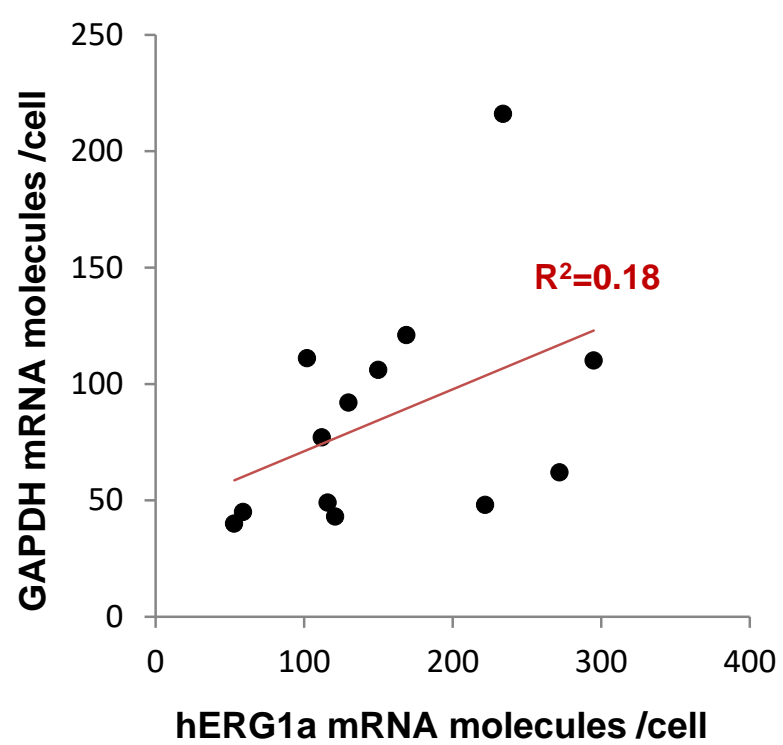

Figure S5: Correlation of mRNA expressions. The number of mRNA molecules detected per cells in double smFISH experiments were plotted for SCN5A and GAPDH (28 cells, a), and $h E R G 1 \mathrm{a}$ and GAPDH (13 cells, b). The Pearson's correlation coefficient $\left(R^{2}\right)$ were calculated for each pairs of mRNAs. 
a
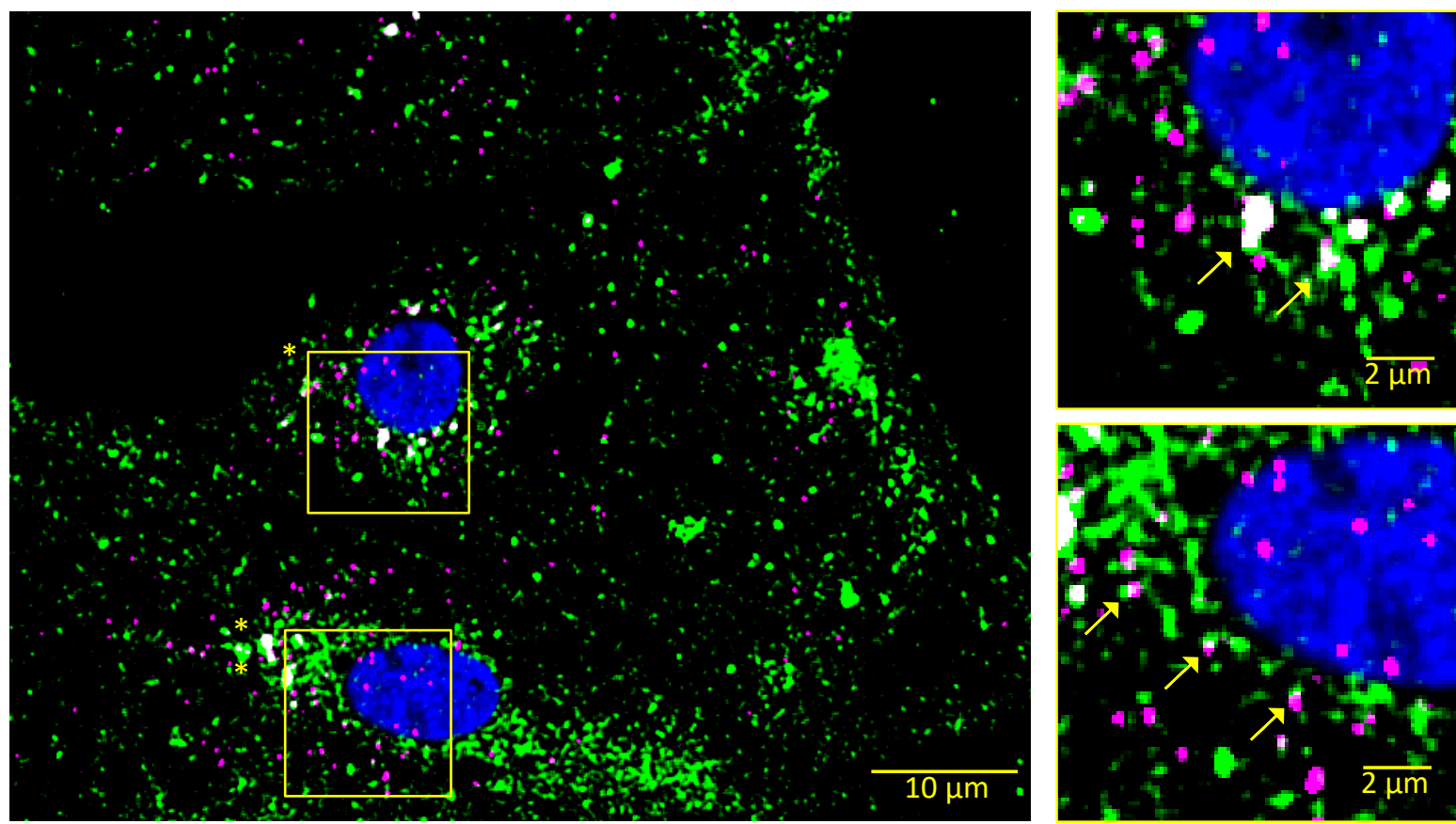

b

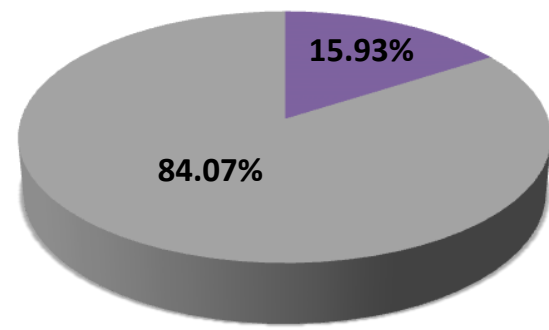

hERG1a mRNA associated with hERG1a protein

Single hERG1a mRNA

hERG1a mRNA

Figure S6: hERG1a mRNA protein interaction. a, Representative confocal images and enlargement (outlined in yellow) of iPSC-CMs subjected to Immunofluorescence combined to smFISH protocol showing the colocalization (yellow arrows) of $h E R G 1$ a mRNA (magenta) and hERG1a protein (green). $\mathbf{b}$, Pie chart showing the percentage of $h E R G 1$ a mRNA population interacting with hERG1a protein revealing that $16 \%$ of $h E R G 1$ a mRNA were actively translated at the moment of fixation. 

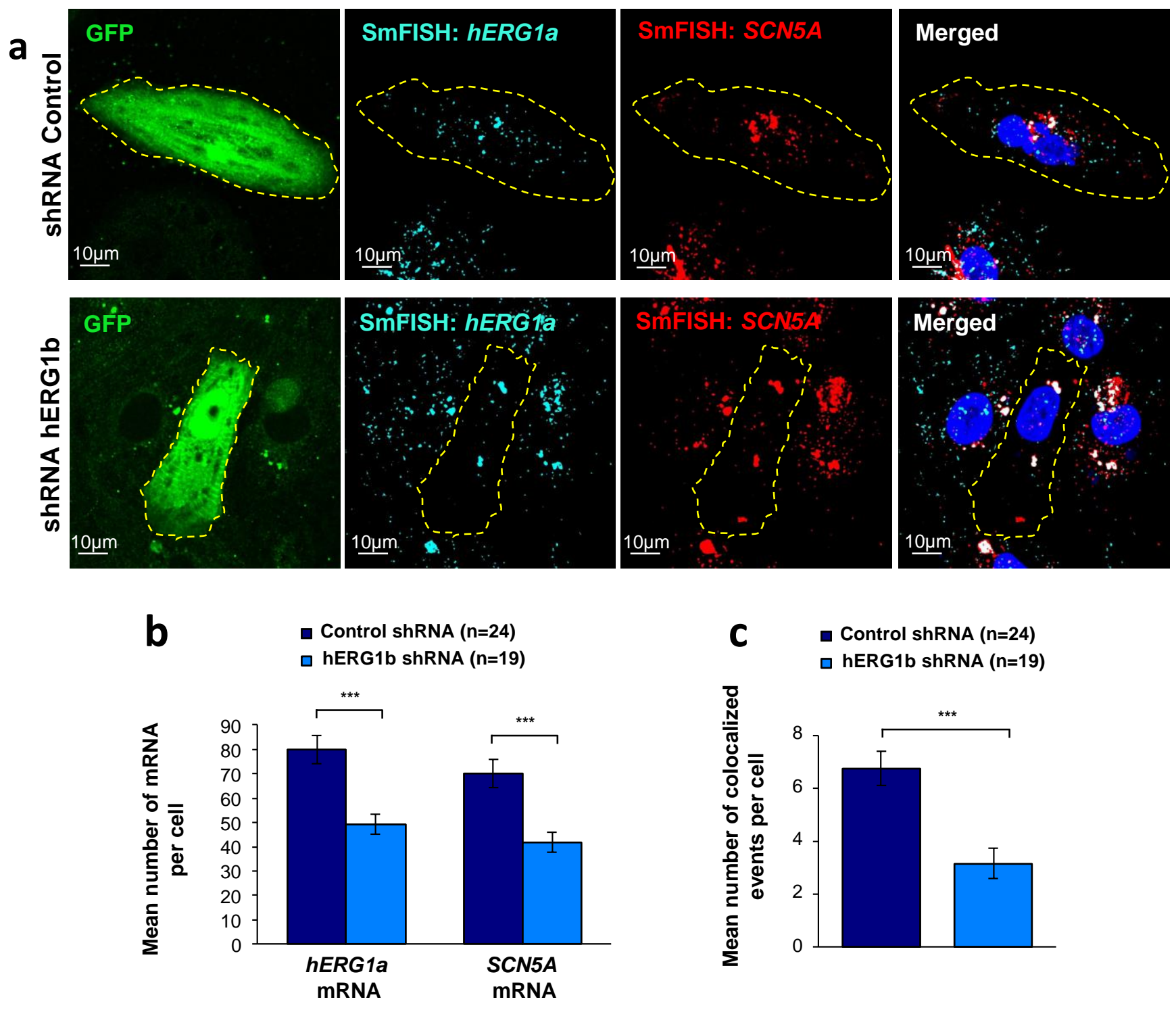

Figure S7: Co-knockdown of $h E R G$ and SCN5A mRNAs by hERG transcript-specific shRNA. a, Representative confocal images of smFISH for $h E R G 1 a$ and SCN5A transcripts in iPSC-CMs transfected with either a control or hERG1b shRNA. b. Histogram of the average number of transcripts detected per cell for $h E R G 1 a$ or SCN5A transcripts in presence of hERG1b shRNA compared to a scrambled shRNA (mean $\pm \mathrm{SE}$ ). c, Histogram of the mean number of $h E R G 1 a$ transcript colocalized with SCN5A transcript in cells silenced for hERG1b compared with control (mean $\pm \mathrm{SE}$ ). 